\title{
Modeling sea-salt aerosol in a coupled climate and sectional microphysical model: mass, optical depth and number concentration
}

\section{T. Fan and O. B. Toon}

Laboratory for Atmospheric and Space Physics, Department of Atmospheric and Oceanic Sciences, University of Colorado, Boulder, USA

Received: 30 September 2010 - Published in Atmos. Chem. Phys. Discuss.: 20 October 2010

Revised: 7 April 2011 - Accepted: 29 April 2011 - Published: 16 May 2011

\begin{abstract}
Sea-salt aerosol mass, optical depth, and number concentration over the global oceans have significant implications for aerosol direct and indirect climate effects. We model sea-salt aerosol in a coupled climate and sectional microphysical model, CAM/CARMA, with aerosol dynamics including sea-salt emission, gravitational sedimentation, dry deposition, wet scavenging, and hygroscopic growth. We aim to find an integrated sea-salt source function parameterization in the global climate model to simultaneously represent mass, optical depth, and number concentration. Each of these quantities is sensitive to a different part of the aerosol size distribution, which requires a size resolved microphysical model to treat properly. The CMS source function introduced in this research, based upon several earlier source functions, reproduces measurements of mass, optical depth and number concentration as well as the size distribution better than other source function choices we tried. However, as we note, it is also important to properly set the removal rate of the particles. The source function and removal rate are coupled in producing observed abundances. We find that sea salt mass and optical depth peak in the winter, when winds are highest. However, surprisingly, particle numbers and $\mathrm{CCN}$ concentrations peak in summer when rainfall is lowest. The quadratic dependence of sea-salt optical depth on wind speed, observed by some, is well represented in the model. We also find good agreement with the wind speed dependency of the number concentration at the measurement location and the regional scale. The work is the basis for further investigation of the effects of sea-salt aerosol on climate and atmospheric chemistry.
\end{abstract}

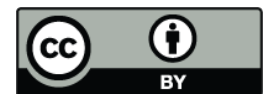

Correspondence to: T. Fan (tianyi.fan@colorado.edu)

\section{Introduction}

Atmospheric sea-salt aerosol (SSA) particles are produced by wind driven processes over the ocean and have sizes from tens of nanometers to several hundred microns. Since SSA does not have a large anthropogenic source it is usually treated as a background aerosol. However, the human impacts on aerosol climate effects have to be investigated based on knowledge of natural aerosols. SSA dominates the particulate mass and is a major contributor to the aerosol optical depth over the remote ocean (Quinn et al., 1998). The scattering of sunlight by SSA particles modifies the radiation budget of the Earth system, which is known as "the aerosol direct effect". SSA accounts for $50 \%$ of the local light scattering over the oceans and could contribute over a third of the column aerosol optical depth according to a compilation of global aerosol observations (Penner et al., 2001). The topof-atmosphere clear sky global annual mean radiative forcing due to sea-salt is estimated between -0.6 and $-5.03 \mathrm{Wm}^{-2}$ according to different models (Winter and Chylek, 1997; Haywood et al., 1999; Jacobson, 2001; Grini et al., 2002; Ayash et al., 2008; Ma et al., 2008). The region with the strongest direct radiative effect is the so-called "roaring forties" around $40^{\circ} \mathrm{S}$. Observations show that the large surface area concentration of SSA makes it the dominant scatterer over this region, not only for the supermicron (radius $>1 \mu \mathrm{m}$ ) aerosol but also for the submicron aerosol (radius $<1 \mu \mathrm{m}$ ) (Quinn et al., 1998; Bates et al., 2002).

Recent measurements indicate the existence of many submicron and ultrafine-mode (radius $<0.1 \mu \mathrm{m}$ ) SSA particles that dominate the SSA number concentration (Clarke et al., 2006; Mårtensson et al., 2003). SSA particles activate as cloud condensation nuclei $(\mathrm{CCN})$ and modify the cloud radiative properties and lifetimes, which is known as "the aerosol indirect effect". SSA is observed to dominate the

Published by Copernicus Publications on behalf of the European Geosciences Union. 
$\mathrm{CCN}$ over the remote ocean where wind speeds are high and/or other aerosol sources are weak (Murphy et al., 1998). They are more readily activated as CCN than sulfate aerosol due to their larger size and low supersaturation threshold (O'Dowd et al., 1999). The inclusion of SSA as small as $0.01 \mu \mathrm{m}$ in a global aerosol model increases $\mathrm{CCN}$ over the Southern Ocean by $150 \%-500 \%$ (Pierce and Adams, 2006). In contrast, if the ultrafine particles are not considered, SSA contributes only $10 \%$ to cloud droplet number (Ayash et al., 2008). Moreover, SSA modulates the behavior of other aerosol species and gaseous precursors from both natural and anthropogenic sources. They provide surface area as a sink for the condensation of low-vapor-pressure gaseous species such as sulfuric and methanesulfonic acid so as to suppress the nucleation of new particles. Oxidation of $\mathrm{SO}_{2}$ is enhanced due to the higher $\mathrm{pH}$ associated with sea-salt droplets both inside and outside the cloud (O'Dowd et al., 1997).

In conclusion, SSA affects the climate system by scattering solar radiation, modifying the properties of clouds in the marine boundary layer, and participating in heterogeneous chemistry. These effects are dominated by SSA burdens in different size ranges. Therefore, uncertainties caused by errors in modeling the SSA production, transport and removal processes in any size range could lead to errors in climate forcing estimates.

In this study, we use a coupled climate-microphysical model to represent the dynamics and microphysical processes affecting SSA on a global scale. The goal of this paper is to test the model's capability to simulate three properties that are highly relevant to the direct and indirect climate effects of SSA: the mass of the aerosols, their optical depth and their number concentration. The results from three emission parameterizations of Gong (2003), Caffrey et al. (2006), and a combined Clarke et al. (2006), Monahan et al. (1986), and Smith et al. (1993) formulation (CMS hereinafter) will be compared. As we will discuss, the mass, the optical depth, and the number of SSA are controlled by distinctly different parts of the size distribution. The advantage of using a sectional microphysical model is that we have the flexibility to control the modeling of the physical processes and track the properties for each aerosol bin size. The following section describes the model setup. The results from the model, and comparisons with observations are given in Sect. 3. Section 4 provides a conclusion.

\section{Model description}

The microphysical model, which is based on the community aerosol and radiation model for atmospheres (CARMA, version 2.3) developed at the University of Colorado/National Aeronautics and Space Administration (NASA) (Toon et al., 1988), has been incorporated into the National Center for Atmospheric Research (NCAR)'s community atmosphere model (CAM, version 3.1) (Collins et al., 2006) following the column physics interface algorithm. CARMA serves as a size-resolved aerosol microphysical component to replace CAM's bulk aerosol model. The coupled model has been applied to study Asian dust (Su and Toon, 2009, 2011), as well as micrometeorites, and noctilucent clouds (Bardeen et al., 2008, 2010). For the purpose of this investigation, the only aerosol species considered is sea-salt. We used 16 mass bins to represent SSA. These mass bins correspond with dry radius bins logarithmically spaced between 0.01 and $15.2 \mu \mathrm{m}$, including 10 submicron and 6 supermicron bins. Throughout the text and figure captions the "radius" is referred to dry radius unless specifically mentioned. Each size bin is treated by CAM as an individual advected tracer (Bardeen et al., 2008). We use 16 bins based on the results from test runs showing that mass concentrations using 16 size bins converge with those using 21 size bins.

We drive the model with 6-hourly National Center for Environmental Prediction (NCEP)/NCAR reanalysis I fields for wind speed, temperature, surface water vapor flux and surface sensible heat flux (Kalnay et al., 1996). The wind field in CAM is interpolated into 30-minute time steps. The model runs in a nudged mode, which means that the meteorology inputs are forced back to interpolated NCEP fields at the beginning of every time step. The horizontal grid spacing is $2^{\circ}$ latitude by $2.5^{\circ}$ longitude. There are 28 vertical layers. The bottom layer is approximately $120 \mathrm{~m}$ thick.

The aerosol processes considered include: (1) sea-salt emission at the surface, (2) turbulent diffusion, (3) transport on a global scale, (4) gravitational sedimentation, (5) dry deposition at the surface, (6) scavenging by clouds and rain, and (7) particle growth by taking up water. Coagulation is not considered in the model as test runs show that it is not an important process even with enhanced number concentrations from the ultrafine particles.

The particle sizes are tracked in the model by the dry mass of sea-salt. Since wet particles smaller than $30 \mu \mathrm{m}$ (which will typically correspond to dry particles smaller than $15 \mu \mathrm{m}$ ) will evaporate to their ambient radius in a time period that is shorter than their lifetime (Fitzgerald et al., 1998; Lewis and Schwartz, 2004), it is assumed in our model that the particles reach equilibrium with the ambient environment instantaneously. The wet radii are calculated based on the model humidity at the time and location of interest as discussed below. Gravitational sedimentation, dry deposition, and optical properties take into account the wet radius of the SSA while turbulence and advective transport do not incorporate the wet radius, although there can be a significant humidity gradient coupled with rapid turbulent mixing (Caffrey et al., 2006).

Assumptions are made to compensate for the features that could not be captured due to the limited temporal and spatial resolution. Weibull wind speed distributions are adopted to represent the effect of wind gusts on SSA production, since the emission flux is a non-linear function of wind speed (Justus et al., 1978). Large particles have a short lifetime due to gravitational sedimentation, which is not well represented in 
a model with coarse vertical resolution. So we correct the sea-salt emission flux based on Hoppel et al. (2005), which mostly affects the large particles.

\subsection{Emission}

There are two major questions about the emission flux: what is the emission rate for different particle sizes and what is the dependence of emission rate on wind speed? The sizeresolved SSA emission flux is also known as the source function. There are numerous proposed source functions based on in-situ measurements, laboratory experiments, or their combination. However, the uncertainty in SSA source functions is large due to difficulty in sampling over the ocean, limitation of the measurement equipment, scarcity of the data, the geographically varying nature of the sea-salt emission, and the differing focuses of the researchers (Lewis and Schwartz, 2004). Our goal is to choose a source function that is suitable for global climate models and capable of representing the mass, optical depth, and number concentrations simultaneously.

Monahan et al. (1986) derived a source function by combining laboratory measurements of droplet number flux from bubbles per unit whitecap area and field measurements of whitecap coverage as a function of wind speed. The wind dependence in the Monahan et al. (1986) source functions is represented by a whitecap coverage function

$W_{\text {cap }}\left(u_{10}\right)=3.84 \times 10^{-6} u_{10}^{3.41}$

where $u_{10}$ is the wind speed at $10 \mathrm{~m}$.

Almost all source functions have followed their approach of using the whitecap area to determine the wind speed dependence of the fluxes. The Monahan et al. (1986) formula $(d F / d r)_{\text {Monahan }}$ which incorporates the wind speed and radius dependence is shown is Table 1.

Figure 1 shows the Monahan et al. (1986) source function for particle number together with several other source functions. The number concentration for all the source functions shown in Fig. 1 increases with wind speed while the shape of the spectrum is unchanged, except for the Caffrey source function. The shape of the Caffrey function changes for wind speeds above $9 \mathrm{~m} \mathrm{~s}^{-1}$ to include spume particles, which are modeled following the Smith et al. (1993) source function. These wind speed dependencies are illustrated in Fig. 2.

Several different physical effects are involved in SSA generation. Bursting bubbles in the foam from the whitecaps yield particles larger than about $1 \mu \mathrm{m}$ from small jets and particles smaller than $1 \mu \mathrm{m}$ from the film making up the bubble. Hence the origins of the particles differ across the size spectrum. The number fluxes for various source functions between 0.1 and $10 \mu \mathrm{m}$ are similar within a factor of about 2. However, extrapolation of the Monahan et al. source function to radii smaller than $0.1 \mu \mathrm{m}$ leads to very large particle production rates (Andreas, 1998; Vignati et al., 2001;

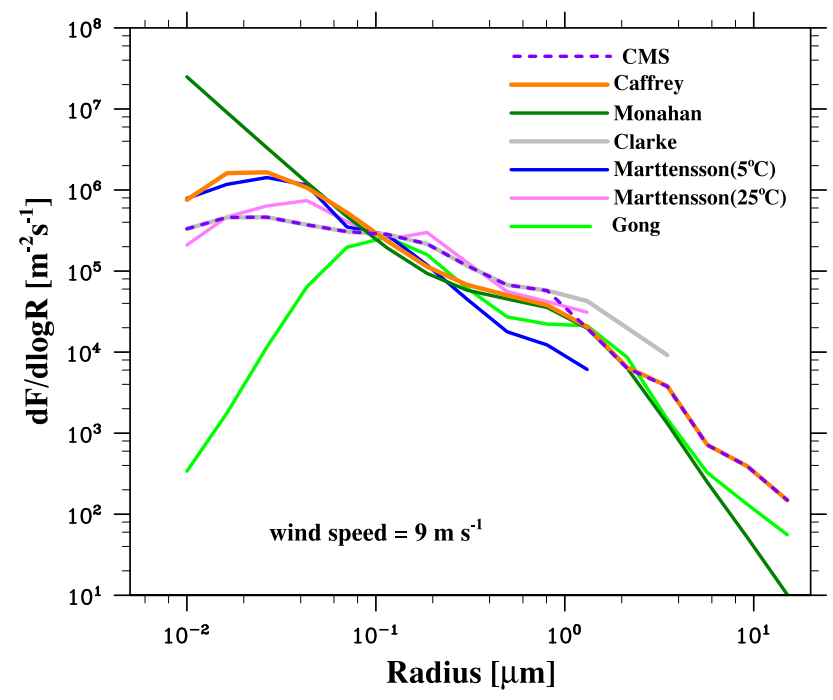

Fig. 1. The number fluxes from several sea-salt source functions as a function of dry radius. All of the source functions except for Gong are corrected for gravitational sedimentation following Hoppel et al. (2005).

Mårtensson et al., 2003). Gong (2003) suggested an extension of Monahan et al.'s source function that covers the size range as low as $0.01 \mu \mathrm{m}$ (see Table 1 for formula). However, Gong's submicron flux is low by many orders of magnitude compared with that from the laboratory measurements of Mårtensson et al. (2003), who developed their source function down to $0.01 \mu \mathrm{m}$ by measuring SSA in a bubble chamber using synthetic seawater. Mårtensson et al. (2003) also measure the SSA emission dependence on temperature and salinity. Clarke et al. (2006) later measured the SSA spectrum in a coastal zone with breaking waves and acquired the flux for the submicron particles. Clarke et al.'s ultrafine SSA number matches Mårtensson et al.'s function at $25^{\circ} \mathrm{C}$ and is also orders of magnitude higher than Gong's flux. Mårtensson et al.'s function predicts increased ultra-fine particle number and decreased number between $0.1-1 \mu \mathrm{m}$ as temperature decreases $\left(5^{\circ} \mathrm{C}\right.$ curve in Fig. 1).

To simulate the SSA mass, optical depth and number, a source function that reasonably covers the whole size range is demanded. However, the applicable size ranges of the schemes mentioned above cut off at various lower or upper limits. For this reason, Caffrey et al. (2006) combined the Clarke/Mårtensson, Monahan and Smith et al. (1993) source functions (see Table 1, $\left.(d F / d r)_{\text {Caffrey }}\right)$. The Smith function is introduced for spume droplets production $\left(\left(d F / d r_{\text {Smith }}\right)\right.$ in Table 1). Spume droplets are formed when the wind shears off wave crests. Studies are available for the production of spume droplets, though data are scarce (Burk, 1984; Stramska, 1987; Andreas, 1990; Smith et al., 1993). Reviews were given in Fitzgerald (1991) and Andreas et al. (1995). Smith et al. (1993) suggested a spume source function with an exponential function of radius and of wind speed up to 
Table 1. Formulas for source functions compared in the paper, unit: $\mathrm{m}^{-2} \mathrm{~s}^{-1} \mu \mathrm{m}^{-1}$.

\begin{tabular}{|c|c|c|}
\hline Source Function & Formula & Size Range \\
\hline Gong (2003) & $\begin{array}{l}(d F / d r)_{\text {Gong }}=1.373 u_{10}^{3.41} r^{-A}\left(1+0.057 r^{3.45}\right) \times 10^{1.607 e^{-B^{2 *}}} \\
A=4.7(1+\Theta r)^{-} 0.017 r^{-1.44}, \quad \Theta=\text { adjustable parameter }=30 \\
B=(0.433-\log r) / 0.433\end{array}$ & $0.01-15 \mu \mathrm{m}$ \\
\hline Caffrey et al. (2006) & $\begin{array}{l}(d F / d r)_{\text {Monahan }}=1.373 u_{10}^{3.41} r^{-3}\left(1+0.057 r^{1.05}\right) \times 10^{1.19 e^{-B^{2}}} \\
B=(0.38-\log r) / 0.65 \\
(d F / d r)_{\text {Caffrey }}=(d F / d r)_{\text {Monahan }} \times W(r) \\
W(r)=1.136^{-r^{-0.855}}\left(1+\frac{0.2}{r}\right) \\
(d F / d r)_{\text {Caffrey }}=\left\{\begin{array}{l}u_{10}<9 \mathrm{~ms}^{-1},(d F / d r)_{\text {Monahan }} \\
u_{10}>9 \mathrm{~ms}^{-1}, \max \left((d F / d r)_{\text {Monahan }},(d F / d r)_{\text {Smith }}\right)\end{array}\right. \\
\times W(r), \\
\text { where } \\
(d F / d r)_{\text {Smith }}=\sum_{i=1}^{2} A_{i} \exp \left\{-f_{1}\left[\ln \left(r_{80} / r_{i}\right)\right]^{2}\right\}, * * \\
f_{1}=3.1, f_{2}=3.3, r_{1}=2.1 \mu \mathrm{m}, r_{2}=9.2 \mu \mathrm{m} \\
\log \left(A_{1}\right)=0.0676 u_{14}+2.43^{*}, \quad \log \left(A_{2}\right)=0.959 u_{14}-1.476\end{array}$ & $0.01-0.15 \mu \mathrm{m}$ \\
\hline CMS Fan and Toon (2010) & $\begin{array}{l}(d F / d r)_{\mathrm{CMS}}=(d F / d r)_{\mathrm{Clarke}}=(d F / d r)_{\mathrm{BW}} \cdot W_{\text {cap }}\left(u_{10}\right) \\
(d F / d r)_{\mathrm{BW}}=\sum_{i=1}^{3} A_{i} \\
A_{i}=\beta_{0}+\beta_{1} D+\beta_{2} D^{2}+\beta_{3} D^{3}+\beta_{4} D^{4}+\beta_{5} D^{5} \\
D=\text { diameter }=2 r . \\
\text { See Table } 1 \text { in }(\text { Clarke et al., } 2006) \text { for } \beta \text { coefficients, } \\
\text { The whitecap coverage } W_{\text {cap }}\left(u_{10}\right)=3.84 \times 10^{-6} u_{10}^{3.41} \\
\text { same as Caffrey et al. }(2006) \text { in size range of } 0.15-15 \mu \mathrm{m}\end{array}$ & $0.8-15 \mu \mathrm{m}$ \\
\hline
\end{tabular}

\footnotetext{
* $u_{10}$ and $u_{14}$ is the wind speed at $10 \mathrm{~m}$ and $14 \mathrm{~m}$, respectively.
}

** $r$ is the dry radius, $r_{80}$ is the radius at $80 \%$ relative humidity.

$32 \mathrm{~m} \mathrm{~s}^{-1}$. Caffrey et al. (2006) took the larger of Monahan and Smith functions for radii from 0.15 to $15 \mu \mathrm{m}$ for wind speed above $9 \mathrm{~m} \mathrm{~s}^{-1}$, which is the threshold wind speed for spume droplets. Below $9 \mathrm{~m} \mathrm{~s}^{-1}$, they used the Monahan scheme alone. To make the Aitken-mode (radius $<0.1 \mu \mathrm{m}$ ) number more like Clarke or Mårtensson, Caffrey et al. (2006) extended the source function down to $0.01 \mathrm{um}$ using the Monahan source function and multiplying the whole size range by a size-dependent factor $W(r)$, where $r$ is dry particle radius. $W(r)$ approaches 1 as the radius increases. As shown in Fig. 1, below $0.1 \mu \mathrm{m}$ Caffrey et al. (2006)'s number flux is about one magnitude higher than Clarke et al. (2006) but matches Mårtensson's function at $5{ }^{\circ} \mathrm{C}$. This order of magnitude difference in fluxes may reflect the wide range of fluxes found by Mårtensson et al. (2003) depending on the temperature of the seawater.

Inspired by Caffrey et al. (2006), we introduce a combined Clarke, Monahan and Smith (CMS) source function as an alternative scheme. The formula of CMS function is, for $r=$ $0.01-0.8 \mu \mathrm{m}$

$$
\begin{aligned}
& (d F / d r)_{\mathrm{CMS}}=\sum_{i=1}^{3}\left(\beta_{0}+\beta_{1} D+\beta_{2} D^{2}+\beta_{3} D^{3}+\beta_{4} D^{4}+\beta_{5} D^{5}\right)(2) \\
& \cdot W_{\text {cap }}\left(u_{10}\right) \cdot r \ln 10, \quad \text { for } r=0.8-15 \mu \mathrm{m} \\
& (d F / d r)_{\mathrm{CMS}} \\
& =\left\{\begin{array}{l}
u_{10}<9 \mathrm{~m} \mathrm{~s}^{-1},(d F / d r)_{\text {Monahan }} \\
u_{10}>9 \mathrm{~m} \mathrm{~s}^{-1}, \max \left((d F / d r)_{\text {Monahan }},(d F / d r)_{\text {Smith }}\right)^{(3)}
\end{array}\right.
\end{aligned}
$$

$D$ is the dry diameter of the sea-salt particles. See Table 1 in Clarke et al. (2006) for $\beta$ coefficients. The $r \ln 10$ factor is to convert $d F / d \log r$ to $d F / d r$. Here we directly adopt Clarke's function below $0.8 \mu \mathrm{m}$ and take the larger of the Monahan and the Smith function above $0.8 \mu \mathrm{m}$ when wind speed exceeds $9 \mathrm{~m} \mathrm{~s}^{-1}$. Notice that we extend the Clarke source function to $0.8 \mu \mathrm{m}$ (compared to $0.15 \mu \mathrm{m}$ in Caffrey function) so that the CMS source function is larger in this size range than the Gong/Caffrey functions and comparable to Mårtensson's function at $25^{\circ} \mathrm{C}$. We make this adjustment because, as we will show later, the Gong and the Caffrey 

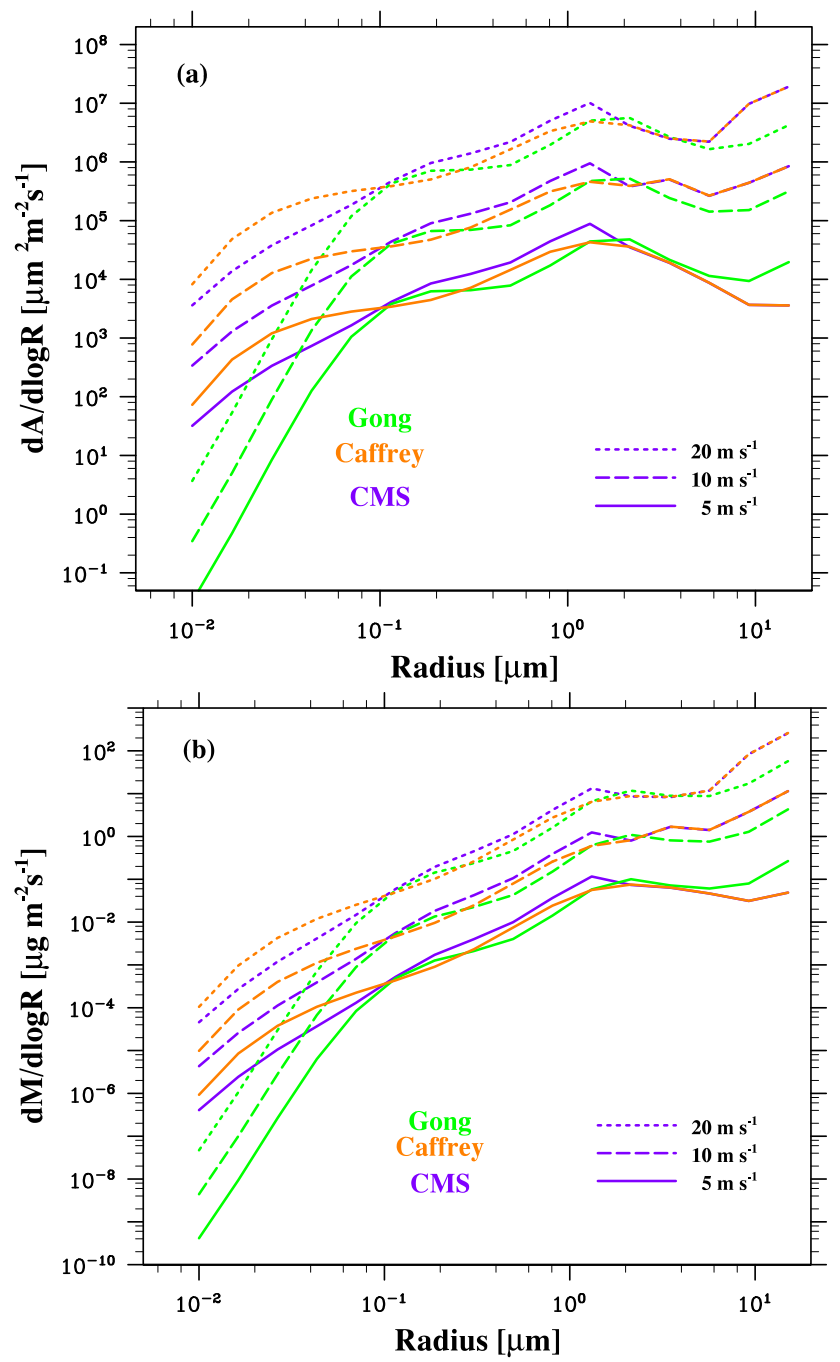

Fig. 2. Gong, Caffrey, and CMS source functions shown for (a) cross-sectional area and (b) mass as a function of dry radius. The three groups of curves represent the size distribution under wind speeds of 5,10 , and $20 \mathrm{~m} \mathrm{~s}^{-1}$ from bottom to top. The source functions are corrected for gravitational sedimentation following Hoppel et al. (2005).

schemes tend to underestimate the optical depth, a quantity dominated by particles between $0.1-1 \mu \mathrm{m}$ in radius.

The effect of temperature on sea-salt emission could be important as Mårtensson et al. (2003) suggest. By introducing a temperature-dependent source function in the GEOSChem global chemical transport model, Jaeglé et al. (2011) reduce the underestimation of particle concentration over cold waters of the high-latitude oceans and the overestimation over warm tropics waters. We could also adopt the Mårtensson function for the size range below $0.8 \mu \mathrm{m}$, but it will introduce another dimension of uncertainty through temperature dependence. We do not find that the observational data base is robust enough to determine if there are latitudinal variations induced in the number of particles by temperature. Also the Mårtensson et al. temperature dependence affects particles larger than $0.1 \mu \mathrm{m}$, but with the opposite effect as for smaller particles. Hence we choose to adopt the simpler Clarke function while keeping in mind that the number flux could be potentially underestimated in cold high latitude oceans or overestimated in warm tropical oceans. We will compare results from Gong, Caffrey, and CMS source functions later in this paper and decide which one can best fit the demands of this research.

Many papers only display the source functions by number as in Fig. 1. However, many properties of the sea-salt are relatively unrelated to the number of particles. In fact number, optical depth, and mass fluxes are each dominated by different size ranges of the source function. Of course, since large particles fall out rapidly, the injected mass at $10 \mathrm{~m}$ is dominated by larger sized particles than are found $60 \mathrm{~m}$ above the sea surface, where the mid-point of our first model layer typically occurs. From the perspective of climate modeling, a model that is only tested against sea-salt mass is not guaranteed to properly represent optical depth or particle number.

Figure 2 shows the cross-sectional area and mass source functions at wind speeds of 5,10 , and $20 \mathrm{~m} \mathrm{~s}^{-1}$ at $10 \mathrm{~m}$ altitude for the Gong, Caffrey, and CMS source functions. As shown in Fig. 1 the number flux is controlled by particles smaller than $0.1 \mu \mathrm{m}$. Figure 2 shows that the area flux is dominated by particles with sizes near $1 \mu \mathrm{m}$, except that the contribution of very large particles becomes significant at high wind speed. SSA area is a critical input to the optical depth calculation. The mass plots in Fig. 2, however, are dominated by particles with sizes near and above $10 \mu \mathrm{m}$. We notice that small slope changes of the Gong source function in the number plot of Fig. 1 translate into a mass peak at the end of the size ranges in Fig. 2. It is not clear in the development of the Gong source function whether the mass peak is meant to be realistic for bubble bursting, or to crudely represent spume particles. The Monahan formulation, which was the basis of the Gong formulation, was not meant to include generation of spume droplets. The Monahan source function does not show a mass peak above $10 \mu \mathrm{m}$ as in the Gong source function.

Generally the sea-salt source function is designed to represent the flux at $10 \mathrm{~m}$ above the ocean surface. However, the mid-point of our model bottom layer is about $60 \mathrm{~m}$. Hoppel et al. (2005) suggested applying a correction factor $f_{\text {ref }}$ directly to the source function to account for the significant vertical gradient of large particles in the first model layer between $10 \mathrm{~m}$ and the layer mid-point:

$f_{\text {ref }}=\left(\frac{\delta}{z_{\text {ref }}}\right)^{\frac{v g}{x}}$

Here $\delta$ is the $10 \mathrm{~m}$ height where the source function is defined, $z_{\text {ref }}$ is the reference height defined as the midpoint of model bottom layer, and $v_{\mathrm{g}}$ is the gravitational sedimentation 
velocity. The turbulence term is $\chi=k u_{*}$, where $k$ is von Karman's constant, $u_{*}$ is the friction velocity, which is obtained by $u_{*}=C_{D}^{1 / 2} u_{10}$, where

$C_{D}=\left\{\begin{array}{l}1.14 \times 10^{-3}, u_{10} \leq 10 \mathrm{~m} \mathrm{~s}^{-1} \\ \left(0.49+0.065 u_{10}\right) \times 10^{-3}, u_{10}>10 \mathrm{~m} \mathrm{~s}^{-1}\end{array}\right.$

$f_{\text {ref }}$ is close to 1 for small particles and decreases as particle size increases. $u_{10}$ is the wind speed at $10 \mathrm{~m}$. We multiply the Gong, Caffrey, and CMS source function by $f_{\text {ref }}$.

Here we assume that aerosols were evenly mixed horizontally in a grid cell. Some grid cells are partly composed of land or sea ice. Therefore, the emission is multiplied by the fraction of the open ocean area in these grids. Emission from leads within sea ice is not considered in our model.

\subsection{Wind field}

Among the environmental variables that influence the SSA production, wind speed is the major factor that controls the area of the whitecaps and hence the SSA fluxes. The lifting of sea-salt, like the lifting of desert dust, depends on the power in the wind, and varies approximately as the third power of the wind speed. Because the SSA flux dependence on the wind speed is non-linear it is necessary to account for the variability in the wind speed. It is also necessary to make sure that the impact of atmospheric stability on the surface stress is properly treated.

The $10 \mathrm{~m}$ wind $u_{10}$ used in the SSA source functions is calculated from the friction velocity $u_{*}$, which is obtained from the wind speed from the model bottom layer. We assume neutral atmospheric stability in finding $u_{10}$ and use the algorithm suggested by Large and Pond (1982). The whitecap observations were mostly taken under neutral atmospheric stability (Monahan and O'Muircheartaigh, 1986). Using this approach the flux is uniquely related to $u_{*}$. However, if instead one used the $u_{10}$ from the CAM model that was calculated from $u_{*}$ using the local stability, then the flux would no longer be uniquely related to $u_{*}$ as it should be. SSA source functions should be cast in terms of $u_{*}$ so that boundary layer stability is properly accounted for, which is how they are cast for dust lifting over land. We conventionally use the notation $u_{10}$ instead of $u_{*}$ in our source functions. However, as just discussed the $u_{10}$ we use is meant to be a pseudo $u_{10}$ to compensate for the inappropriate use of $u_{10}$ in the sea-salt source functions.

We apply the probability distribution of the wind speed in the source function to represent the non-linearity of wind speed on SSA emission:

$\frac{d F}{d r}=F(r) \int_{u_{0}}^{\infty} u^{3.41} p(u) d u$

Here the source function is divided into a size dependent part, $F(r)$, and a wind speed dependent part, $\int_{u_{0}}^{\infty} u^{3.41} p(u) d u . F(r)$ depends on the source functions used, which are given in Table 1. $u_{0}$ is the threshold wind speed below which there is no SSA production. $u_{0}$ is taken to be $4 \mathrm{~m} \mathrm{~s}^{-1}$ in the model. $u$ is the mean wind speed. $p(u)$ is the two-parameter Weibull distribution having the form

$p(u)=\left(\frac{k}{c}\right)\left(\frac{u}{c}\right)^{k-1} \exp \left[-\left(\frac{u}{c}\right)^{k}\right]$

with $k$ as the shape parameter and $c$ as the scale parameter.

We follow method 5 in Justus et al. (1978) to calculate the shape and scale parameter,

$k=0.94 \sqrt{u}$

$c=u[\Gamma(1+1 / k)]^{-1}$

for average sub-grid wind speed variability. $\Gamma(a)$ is a gamma function defined by

$\Gamma(a)=\int_{0}^{\infty} t^{a-1} e^{-t} d t$

By solving the integral in Eq. (6), we have

$$
\begin{aligned}
& \frac{d F}{d r}=F(r) c^{3.41} \Gamma\left(\frac{3.41}{k}+1,\left(\frac{u_{0}}{c}\right)^{k}\right), \\
& \frac{d F}{d r}=F(r)\left[\frac{u}{\Gamma(1+1 / k)}\right]^{3.41} \Gamma\left(\frac{3.41}{k}+1,\left(\frac{u_{0} \Gamma(1+1 / k)}{u}\right)^{k}\right)
\end{aligned}
$$

in which $\Gamma(a, x)$ is the incomplete gamma function defined by

$$
\Gamma(a, x)=\int_{x}^{\infty} t^{a-1} e^{-t} d t
$$

\subsection{Gravitational sedimentation and dry deposition}

The particles are moved down by gravitational sedimentation in each layer of the model, while the particles are removed by dry deposition in the bottom layer. Gravitational sedimentation velocity, $v_{\mathrm{g}}$, is calculated by CARMA which first makes an estimate for laminar flow (Reynolds number $<<1)$ and then corrects the drag coefficient for turbulent flow (Reynolds number $>1$ ). The formulas are in Table 2. Examples of the gravitational sedimentation velocity are shown in Fig. 3. $v_{\mathrm{g}}$ varies little with wind speed and varies a little with location since the relative humidity and hence the wet radius depend on location.

Dry deposition of SSA particles refers to the transfer of SSA particles to the surface by gravitational sedimentation, turbulent transfer, Brownian diffusion, impaction, and interception by waves. It is reasonable to assume that the sea-salt particles will not rebound at the ocean surface. The dry deposition flux $f_{\mathrm{d}}$ at a reference height is proportional to the mean number concentration $n$

$f_{\mathrm{d}}=n \times v_{\mathrm{d}}$ 
Table 2. Dry deposition scheme.

\begin{tabular}{|c|c|c|}
\hline Item & Formula & Parameter settings \\
\hline $\begin{array}{l}\text { Gravitational } \\
\text { sedimentation } \\
\text { velocity }\end{array}$ & $\begin{aligned} v_{\mathrm{g}} & =\frac{2}{9} \frac{r_{\mathrm{p}}^{2} \rho_{\mathrm{p}} g C_{c}}{\mu}, \text { laminar } \\
v_{\mathrm{g}} & =\frac{\mu R e}{2 \rho r_{\mathrm{p}}}, \text { turbulent }\end{aligned}$ & $\begin{array}{l}r_{\mathrm{p}}=\text { wet particle radius, } \\
\rho_{\mathrm{p}}=\text { wet particle density } \\
g=\text { gravitational acceleration } \\
\mu=\text { dynamic viscosity of air }=1.7 \times 10^{-5}, \\
C_{c}=\text { slip correction factor } \\
\quad=1+\frac{\lambda}{r_{\mathrm{p}}}\left[1.257+0.4 \exp \left(-\frac{1.1 r_{\mathrm{p}}}{\lambda}\right)\right] \\
\lambda=\text { mean free path of air fluid. }\end{array}$ \\
\hline $\begin{array}{l}\text { Aerodynamic } \\
\text { resistance }\end{array}$ & $\begin{array}{l}\text { Ocean/sea ice } \\
R_{\mathrm{a}}=\frac{\ln \left(z_{r} / z_{0}\right)-\psi_{H}}{\kappa u_{*}} \\
\text { Land from CAM land model }\end{array}$ & $\begin{array}{l}z_{r}=\text { center of bottom layer, } \\
z_{o}=\text { roughness length }=0.0001 \text { (ocean), } 0.04 \\
\text { (sea ice) } \\
\kappa=\text { Von Karman constant }=0.4 \\
\psi_{h}=\text { stability function. } \\
u_{*}=\text { friction velocity }\end{array}$ \\
\hline $\begin{array}{l}\text { Surface layer } \\
\text { resistance }\end{array}$ & $R_{\mathrm{S}}=\frac{1}{\varepsilon_{0} u_{*}\left(E_{\mathrm{B}}+E_{\mathrm{IM}}+E_{\mathrm{IN}}\right) R_{1}}$ & $\begin{array}{l}R_{1}=\text { fraction of particles that stick to the sur- } \\
\text { face }=1 \\
\varepsilon_{0}^{*}=\text { empirical constant }=1\end{array}$ \\
\hline $\begin{array}{l}\text { Brownian diffusion } \\
\text { efficiency }\end{array}$ & $E_{\mathrm{B}}=S c^{-\gamma}$ & $\begin{array}{l}S c=\text { Schmidt Number }=v_{\mathrm{a}} / D_{\mathrm{B}}, \\
\nu_{\mathrm{a}}=\text { kinetic air viscosity } \\
D_{\mathrm{B}}=\text { Brownian diffusivity }=\frac{k T}{6 \pi \rho_{\mathrm{a}} v_{\mathrm{a}} r} C_{c}, \\
k=\text { Boltzmann constant, } \\
T=\text { temperature, } \\
\rho_{\mathrm{a}}=\text { air density. } \\
\gamma=1 / 2 \text { for water surface }\end{array}$ \\
\hline $\begin{array}{l}\text { Impaction } \\
\text { efficiency }\end{array}$ & $E_{\mathrm{IM}}=10^{-3 / S t}$ & Stokes number $=\frac{v_{\mathrm{g}} u_{*}^{2}}{g v_{\mathrm{a}}}$ \\
\hline $\begin{array}{l}\text { Interception } \\
\text { efficiency }\end{array}$ & $E_{\mathrm{IN}}=0$ & Neglected in this research \\
\hline
\end{tabular}

${ }^{*} \varepsilon_{0}=3$ in Zhang et al. (2001). Since it is an empirical constant, we choose 1 in our simulation.

where $v_{\mathrm{d}}$ is the dry deposition velocity. In the model, the reference height is the midpoint of the bottom layer, consistent with the height of the concentration. We use the method described in Zhang et al. (2001) to calculate dry deposition velocity

$v_{\mathrm{d}}=v_{\mathrm{g}}+\frac{1}{R_{\mathrm{a}}+R_{\mathrm{S}}}$

In the viscous sublayer, which is $0.1-1 \mathrm{~mm}$ thick above the surface, the SSA particles are mainly transported by Brownian diffusion, impaction and gravitational sedimentation. In the surface layer, which extends from above the viscous sublayer to the reference height, downward flux is dominated by turbulent diffusion and gravitational sedimentation. The transport of SSA particles is assumed to be retarded by the aerodynamic resistance, $R_{\mathrm{a}}$, in the surface layer, and the surface resistance, $R_{\mathrm{S}}$, in the viscous sublayer. $R_{\mathrm{a}}$ depends on the atmospheric stability and surface roughness and is independent of aerosol species. The surface resistance of the viscous sublayer, $R_{\mathrm{S}}$ depends on particle size, atmospheric conditions and surface roughness. $R_{\mathrm{S}}$ is determined by Brownian diffusion, impaction, and interception, whose collection efficiencies are represented by $E_{\mathrm{B}}, E_{\mathrm{IM}}$, and $E_{\mathrm{IN}}$, respectively. The impaction is caused by the failure of an SSA particle to respond rapidly to non-uniform flow near the surface. Interception happens when the particle passes an obstacle at a 


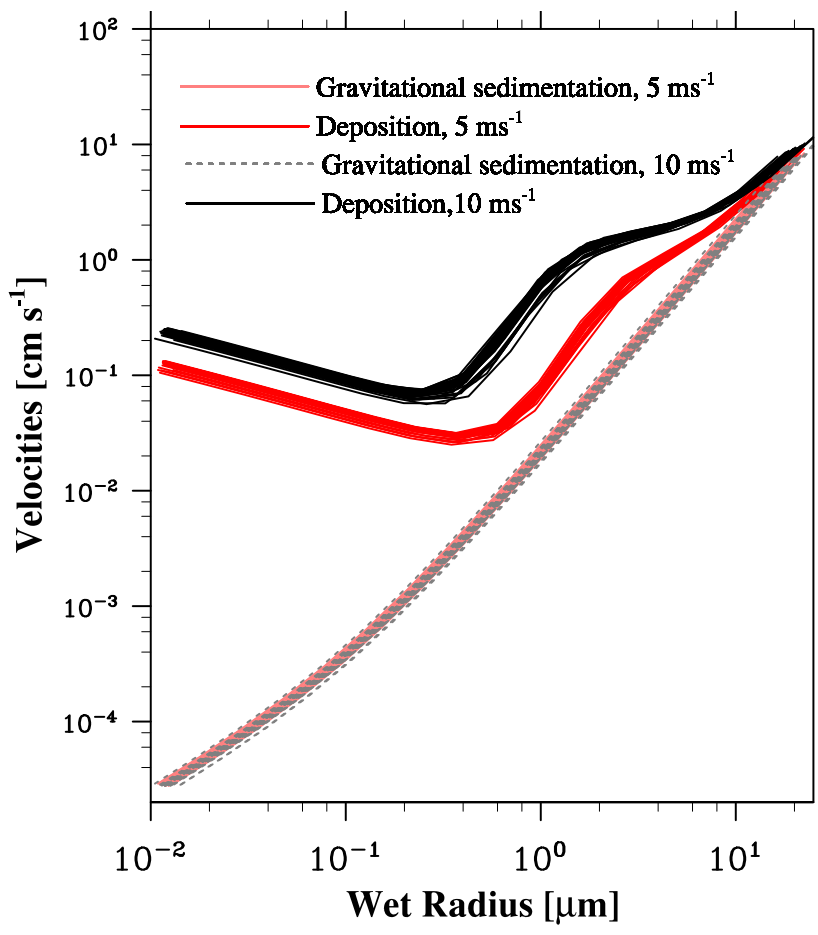

Fig. 3. Gravitational velocities and deposition velocities at the grid cells where wind speeds are $10 \mathrm{~m} \mathrm{~s}^{-1}$ and $5 \mathrm{~m} \mathrm{~s}^{-1}$ over the ocean. Variations of the curves reflect the difference in relative humidity and temperature at different locations.

distance shorter than its physical dimensions. The formulas for each term are listed in Table 2.

In the model the deposition velocities for land, ocean and sea ice are treated separately. The aerodynamic resistance over land is calculated in the CAM land model with detailed land types. Over the ocean and ice we use the method introduced in Seinfeld and Pandis (1998) with roughness lengths of 0.0001 and $0.04 \mathrm{~m}$, respectively. If the grid cell contains multiple surface types, the area fraction-weighted deposition velocity is used.

Figure 3 shows the dry deposition velocity over representative oceanic grid cells at wind speeds of $5 \mathrm{~m} \mathrm{~s}^{-1}$ and $10 \mathrm{~m} \mathrm{~s}^{-1}$. Gravitational sedimentation dominates the removal of particles larger than $20 \mu \mathrm{m}$ in wet radius, while the surface resistance terms dominate the removal rate of small particles. Dry deposition is least efficient for particles between 0.1 and $1 \mu \mathrm{m}$ in radius. The velocities are larger at higher wind speeds, indicating a faster removal rate. Both the emission and dry deposition rates are larger at higher wind speeds.

The tendency of the constituent due to dry deposition can be calculated explicitly,

$\frac{C^{\tau}-C^{\tau-1}}{\Delta \tau}=v_{\mathrm{d}} \frac{C^{\tau}}{\Delta x}$ in which $C^{\tau}$ is concentration of a particular constituent, here SSA, at time $\tau$. $\Delta \tau$ and $\Delta x$ are time and space increments. In our model, to prevent negative concentrations of very large particles that can be caused by rapid removal in a model time step, we change to the implicit method so that the concentrations decrease exponentially in time, i.e.,

$\frac{C^{\tau+1}-C^{\tau}}{\Delta \tau}=v_{\mathrm{d}} \frac{C^{\tau+1}}{\Delta x}$

It should be noted that Eq. (17) is not the exact solution to the problem. However, it is equally as accurate as the explicit method and does not yield negative concentrations for large deposition velocities.

\subsection{Hygroscopic growth}

Sea-salt particles take up water easily and grow in size. The hygroscopic growth affects gravitational sedimentation and dry deposition due to the change of both particle size and density. The variation of dry deposition velocity between locations, represented in Fig. 3 by the bundles of curves, is due to the difference in hygroscopic growth at different locations. It will also affect the optical depth calculation. The wet radius is calculated using a parameterization as a function of relative humidity by Gerber (1985),

$r_{\mathrm{w}}=\left[\frac{C_{1} r_{\mathrm{d}}^{C_{2}}}{C_{3} r_{\mathrm{d}}^{C_{4}}-\log \mathrm{RH}}+r_{\mathrm{d}}^{3}\right]^{1 / 3}$

where $C_{1}=0.7674, C_{2}=3.079, C_{3}=2.573 \times 10-11$, and $C_{4}=-1.424 . r_{\mathrm{w}}$ and $r_{\mathrm{d}}$ are the wet and dry radius in $\mathrm{cm}$. The relative humidity values used in this expression are for the middle of our model layers. Figure 4 shows the ratio of wet radius to dry radius at different relative humidity values. Noting that Gerber's formula cannot be extrapolated to high relative humidity conditions, we limit the surface relative humidity to be less than $98 \%$ when we calculate the wet radius to avoid unrealistic optical depths. The theoretical base for this choice follows the argument in $\$ 2.5 .3$ of Lewis and Schwartz (2004). The equilibrium vapor pressure is nearly proportional to the concentration for dilute solution like seawater. The mole fraction of water in seawater of salinity $35 \%$ is very close to 0.98 . The vapor pressure of water in equilibrium with a seawater droplet is therefore expected to be $98 \%$ of the vapor pressure of water at the same temperature. Thus, at formation, a drop of seawater of salinity $35 \%$ ejected in to the atmosphere has a water vapor pressure that corresponds to $98 \%$ relative humidity in air at the temperature of the drop. Of course clouds form in our model so portions of grid boxes have higher humidity values than $98 \%$. However, it would be unusual for an entire GCM gridbox to be supersaturated.

The wet density, $\rho_{\mathrm{w}}$, is calculated by

$\rho_{\mathrm{w}}=\left(\rho r_{\mathrm{d}}^{3}+\rho_{\mathrm{H}_{2} \mathrm{O}}\left(r_{\mathrm{w}}^{3}-r_{\mathrm{d}}^{3}\right)\right) / r_{\mathrm{w}}^{3}$ 


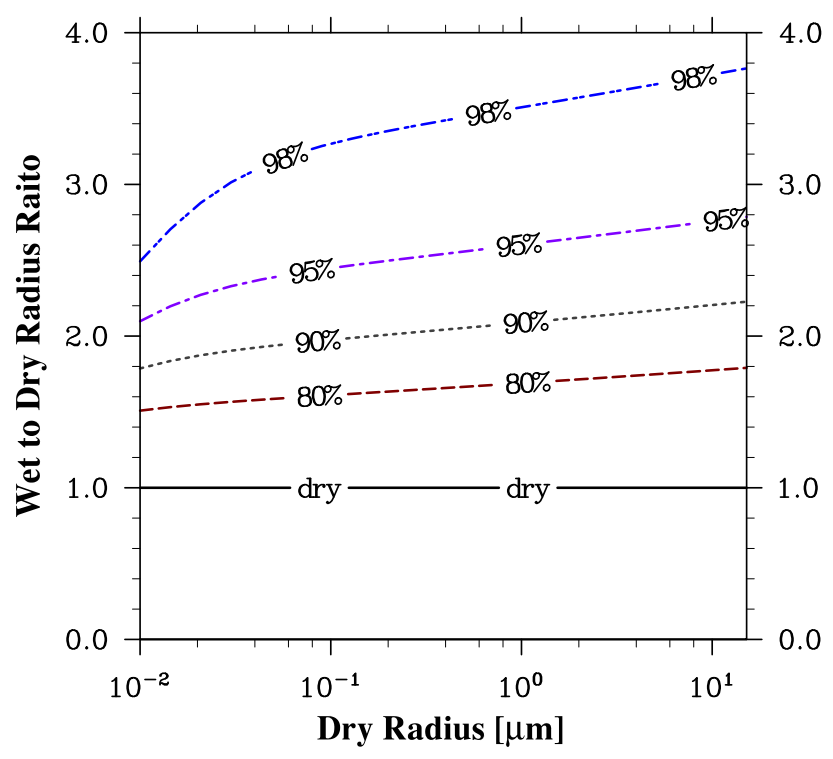

Fig. 4. The ratio of wet to dry radius at different relative humidity values using Gerber (1985).

Here $\rho$ is the density of dry sea-salt having a value of $2.17 \mathrm{~g} \mathrm{~cm}^{-3}$.

\subsection{Wet scavenging}

We utilize the wet scavenging procedure for aerosol in CAM, which accounts for both in-cloud and below-cloud scavenging. The below-cloud scavenging, or washout, follows Dana and Hales (1976) and Balkanski et al. (1993), assuming that both rain and snow remove aerosol below the cloud. The mixing ratio loss rate by below-cloud scavenging, $L_{W, \mathrm{bc}}$, is calculated by

$L_{W, \mathrm{bc}}=\frac{\Lambda}{P} P q$

where $\frac{\Lambda}{P}$ is the washout coefficient $(\Lambda)$ normalized to unit rainfall rate $(P)$. The default washout coefficient in CAM wet scavenging scheme is $0.1 \mathrm{~mm}^{-1}$. $P$ is precipitation in $\mathrm{mm} \mathrm{h}^{-1}$, which could be rain or snow. $q$ is the aerosol mass mixing ratio.

The CAM in-cloud scavenging scheme assumes that a soluble fraction of aerosol particles resides in the cloud water and is later removed with the fraction of cloud water that is converted to rain. This soluble fraction is called the solubility factor, ranging from 0 to 1 , which also decides the percentage of aerosol dissolved in rain or snow droplets, so it affects both below-cloud and in-cloud scavenging. It is further assumed that the aerosol in the rain can be released back to the atmosphere if the rain evaporates.

The wet scavenging rate in CAM is tied to cloud parameterizations including the cloud fraction, cloud water, and production rate of precipitation, etc. It has been noticed that

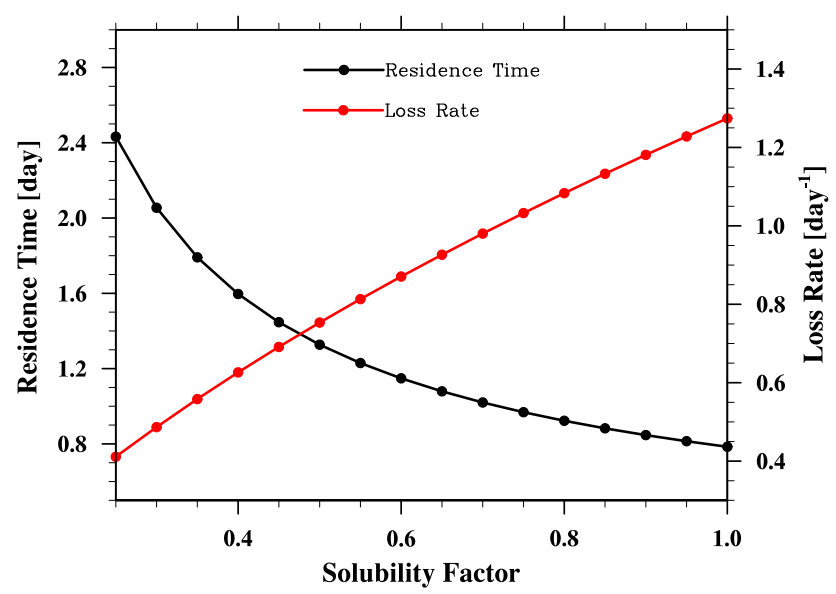

Fig. 5. The mass wet scavenging residence time and loss rate at solubility factors from 0.25 to 1.0 .

CAM among many other global models produces more persistence rainfall than observed (Deng et al., 2007), which leads to overestimated wet scavenging. We are aware of a bug in the wet scavenging code that has recently been found in CAM3.1 and its later versions. However, reasonable lifetimes can still be obtained by tuning the parameters, i.e., the solubility factor.

We adjust the solubility factor in our model by tuning the wet scavenging lifetime to a reasonable range. In an idealized case where only emission and wet scavenging is turned on, the tendency of the concentration $C\left(\mathrm{~kg} \mathrm{~m}^{-2}\right)$ is calculated as $\frac{\delta C}{\delta t}=S-L_{\text {wet }} C$, where $S$ is the emission rate $\left(\mathrm{kg} \mathrm{m}^{-2} \mathrm{~s}^{-1}\right)$, and $L_{\text {wet }}$ is the loss rate due to wet scavenging $\left(\mathrm{s}^{-1}\right)$. When equilibrium is reached $\left(\frac{\delta C}{\delta t}=0\right), L_{\text {wet }}=\frac{S}{C}=1 / \tau_{\text {wet }}$. Here $\tau_{\text {wet }}$ is the wet scavenging residence time (s). Figure 5 shows the variations of the global-averaged residence time and loss rate with the solubility factor at equilibrium. The mean wet scavenging rate for sea-salt reported in 12 models is $0.79 \mathrm{day}^{-1}$, equivalent to a residence time of 1.26 day (Textor et al., 2006). The corresponding solubility is 0.55 . However, the lifetime varied considerably between models. Therefore, we considered solubility factors of $0.3,0.5$, and 0.8 in our model simulations.

\section{Results}

\subsection{Mass concentration}

We compare the modeled mass concentration with the measurements at eight coastal sites from the University of Miami global network (Savoie and Prospero, 1977) in 1994 (SP data hereinafter). The sodium mass is measured by flame atomic absorption with a one-standard deviation uncertainty of $2 \%$. The mass of sodium is then multiplied by 3.252 to retrieve the mass of sodium chloride. Uncertainty may arise from 

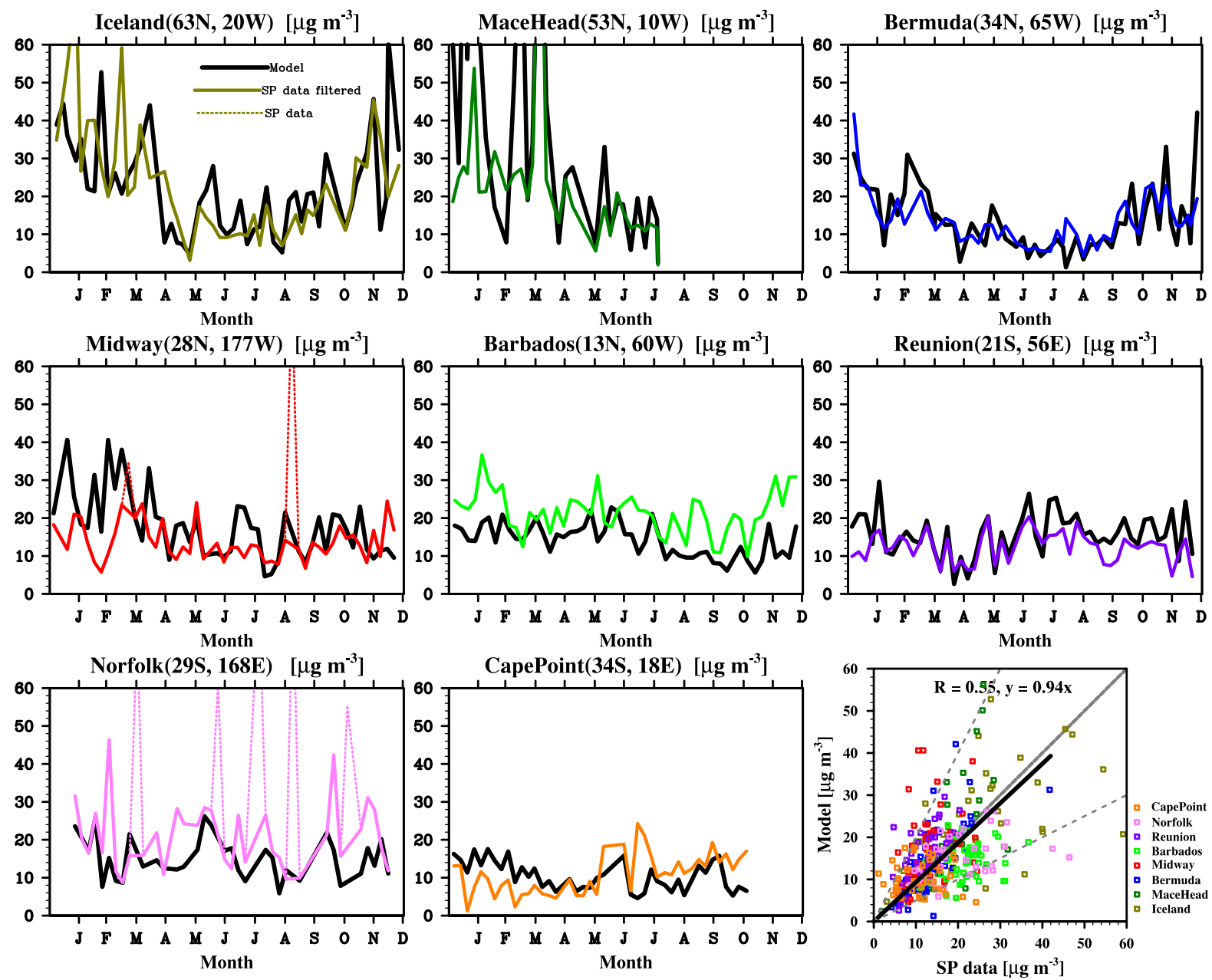

Fig. 6. Seasonal variations and scatter plot of mass concentrations in the marine boundary layer comparing the model results to the measurements at eight coastal sites by the University of Miami global network (SP data, Savoie and Prospero, 1977) in 1994. We used the CMS source function with a solubility factor of 0.5 . The solid line in the scatter plot is the total linear fit to all the data. The grey short dash line is the one-to-one line and the grey long dashed lines are the one-to-two and two-to-one lines.

the different samplers they used and the varying locations from the shoreline at different sites. For further details of the source of uncertainties, refer to Savoie et al. (1994). To minimize island effects on their data, SP used wind sensors to control the sampler pumps so that the wind during the measurements was off the ocean at a speed greater than $1 \mathrm{~m} \mathrm{~s}^{-1}$. Comparisons of grid averaged SSA mass to data measured at a point assumes the point is representative of the grid, but SP do not provide confirmation that their point samples represent any wider region.

We use the NCEP reanalysis for 1994 to drive the model to capture year-to-year variations that would not be captured by free model runs. As the CMS and the Caffrey source function are similar in the large particle range, we only compare the CMS and the Gong source functions. We also test three solubility factors of $0.3,0.5$, and 0.8 . The measurements were mostly obtained on a daily or weekly basis. To align the model results to the measurements in the same time frame, we average daily data to weekly data and average model results for the same days as in the measurements. There are times when extreme events occur at several sites (i.e., Midway and Norfolk) that dominate the mean mass for the month. The model is not able to pick up the extreme events possibly because they were localized to the measuring site as opposed to grid-wide events. In Fig. 6 we provide filtered and unfiltered data. We filter the extreme events in the SP data by eliminating data points outside one standard deviation of the weekly data in 1994 at Midway Island and Norfolk. However, we do not filter the model values. In Table 3, and the correlation plot in Fig. 6, we use the filtered data.

The slopes and the correlation coefficients of the linear fits between measurements and model results are shown in Table 3 for the CMS and Gong source functions. The simulations for both source functions are only weakly dependent 
Table 3. Slopes, correlation coefficients, and normalized mean biases of the linear fits of the measured and modeled mass and optical depth in 1994. The mass data are from the University of Miami global network of aerosol measurements (Savoie and Prospero, 1977). The optical depth data follows the wind speed dependence measured at Mace Head (Mulcahy et al., 2008).

\begin{tabular}{lrrrr|rrr}
\hline Source & Solubility & \multicolumn{3}{c|}{ Mass } & \multicolumn{3}{c}{ Optical Depth } \\
\cline { 3 - 8 } function & factor & Slope & Correlation & $\begin{array}{r}\text { Normalized } \\
\text { mean bias }\end{array}$ & Slope & Correlation & $\begin{array}{r}\text { Normalized } \\
\text { mean bias }\end{array}$ \\
\hline Gong & 0.3 & 0.83 & 0.53 & 0.04 & 0.70 & 0.95 & -0.34 \\
Gong & 0.5 & 0.72 & 0.48 & -0.09 & 0.51 & 0.93 & -0.51 \\
Gong & 0.8 & 0.62 & 0.42 & -0.20 & 0.40 & 0.92 & -0.62 \\
CMS & 0.3 & 1.10 & 0.58 & 0.34 & 1.33 & 0.94 & 0.31 \\
CMS & 0.5 & 0.94 & 0.55 & 0.14 & 0.97 & 0.93 & -0.04 \\
CMS & 0.8 & 0.79 & 0.51 & -0.01 & 0.73 & 0.91 & -0.28 \\
\hline
\end{tabular}

on the solubility factor, which is not surprising since the sink for the large particles that dominate the mass has a significant component due to sedimentation. Figure 6 demonstrates that the model using CMS source function and the solubility factor of 0.5 captures the seasonal variation at the eight coastal sites reasonably well. The scatter plot between measurements and model results after filtering the extreme events at the eight sites is also given in Fig. 6. There are systematic biases in some specific sites. The model underestimates at Barbados and Norfolk most of the time and overestimates at Midway Island and Reunion. However, as seen from the scatter plot, the monthly averages are relatively evenly centered on the linear fit, which means the biases with opposite signs cancel out with each other to some extent. The slope of scatter plot is 0.94 and the correlation is 0.55 . The normalized mean bias, which is the averaged ratio of the difference of the model and observation to the observation, is 0.14 . The model runs using Gong source function underestimates the SP data but reproduce the seasonal variation reasonably well. The slope is 0.72 and the normalized mean bias is -0.09 using Gong source function with solubility factor of 0.5 .

The CMS source function includes the spume droplet production at wind speed higher than $9 \mathrm{~m} \mathrm{~s}^{-1}$ while the Gong source function does not produce spume at high wind speed. It is not realistic for the Gong source function to have high emission rates for particles larger than $1 \mu \mathrm{m}$ at low wind speed $\left(5 \mathrm{~m} \mathrm{~s}^{-1}\right)$ as shown in Fig. 2b. Likewise, neglect of spume causes the Gong source function to predict lower emission than the CMS source function at high wind speeds. Table 3 shows that the CMS source function comparison with data has a higher correlation and a slope closer to unity than the Gong source function. For all of these reasons, we consider CMS to be more realistic as a function of wind speed.

The source functions include the Hoppel et al. (2005) large particle gradient correction. The total global averaged mass concentration using the Hoppel correction is decreased by $14.6 \%$ compared to that without the Hoppel correction. The correction for gradients of large particles in thick model layers near the surface influences the prediction of mass concen- tration and should be considered in models with low vertical resolution.

Note that for particles in the 0.1 to $1 \mu \mathrm{m}$ size range the Mårtensson function would lower the number of particles by up to one order of magnitude at $5{ }^{\circ} \mathrm{C}$ relative to all other functions (Fig. 1). This size range contributes about $20 \%$ to the total mass according to CMS source function. However, the data in winter at high northern latitudes (for example, Iceland and Mace Head in Fig. 6) does not indicate a seasonal error which one might expect if such a strong temperature dependence occurred.

SSA mass concentration over continents is a good indicator of the removal processes as there is no SSA source over land. Figure 7 shows the submicron SSA mass concentration over the United States in 2006 compared with the IMPROVE (Interagency Monitoring of Protected Visual Environments, DeBell et al., 2006) dataset. The loss rate for submicron particles should be dominated by washout and rainout. The IMPROVE data measures the chloride ion over more than 200 sites in the United States. To obtain the seasalt mass the chloride concentration is multiplied by 1.8 to represent the sodium ions, which are not analyzed by IMPROVE. Underestimation by IMPROVE of sea-salt mass results from chlorine depletion in the reaction of SSA with gaseous nitrate acid. The minimum/maximum SSA mass concentrations are $0.014 / 2.18 \mu \mathrm{g} \mathrm{m}^{-3}$ for the IMPROVE data and $0.018 / 4.89 \mu \mathrm{g} \mathrm{m}^{-3}$ for the model. Model results are higher (mainly at coastal sites) but comparable to the IMPROVE data, which indicates the model has reasonable removal mechanisms. The low horizontal resolution of the model $\left(2^{\circ} \times 2.5^{\circ}\right)$ may be a factor in some of the disagreement between the model and data.

\subsection{Optical depth}

The aerosol optical depth, $\tau$, is the vertically integrated aerosol extinction from the bottom to the top of atmosphere. It is calculated in the model as 

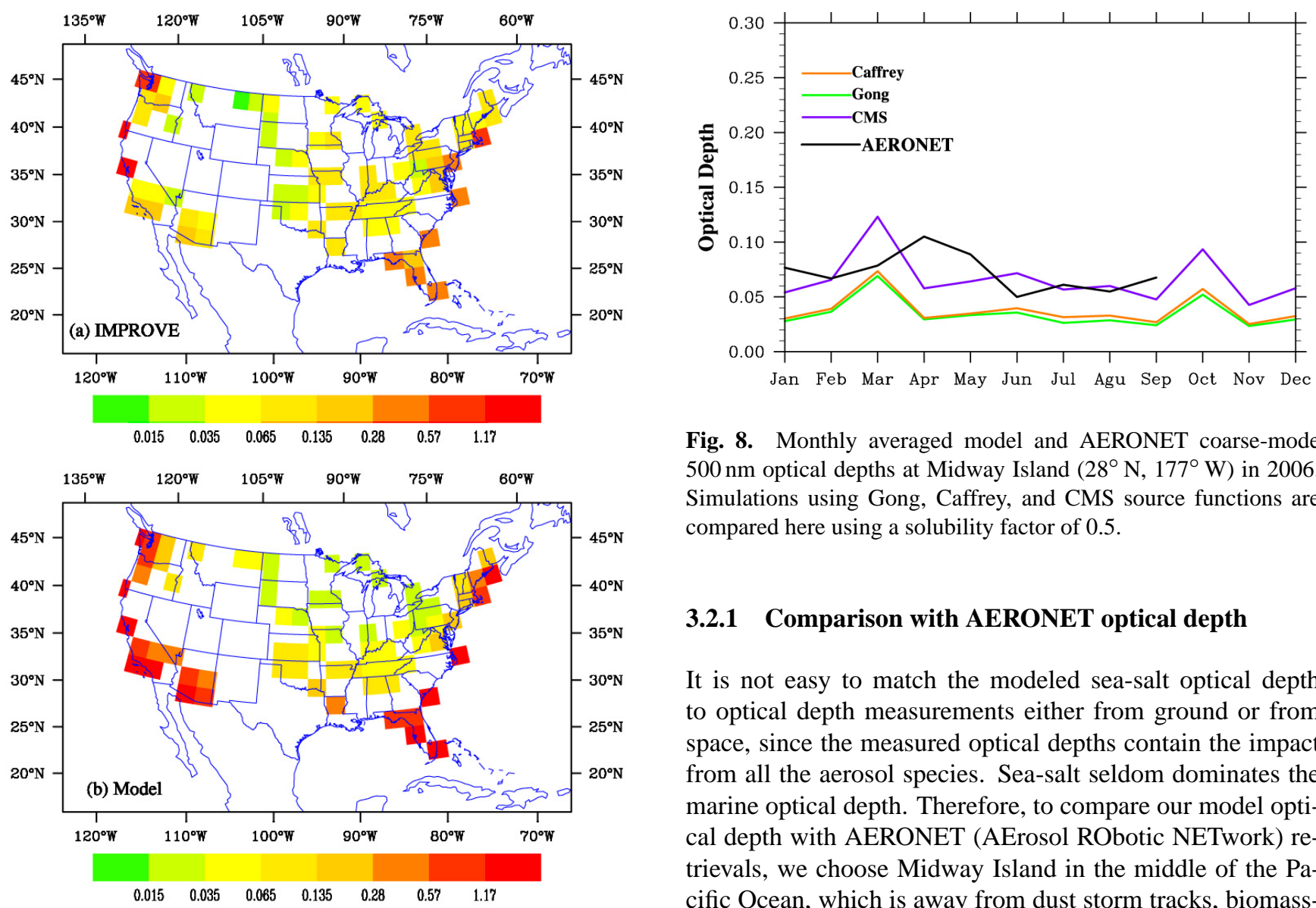

Fig. 8. Monthly averaged model and AERONET coarse-mode $500 \mathrm{~nm}$ optical depths at Midway Island $\left(28^{\circ} \mathrm{N}, 177^{\circ} \mathrm{W}\right)$ in 2006. Simulations using Gong, Caffrey, and CMS source functions are compared here using a solubility factor of 0.5 .

\subsubsection{Comparison with AERONET optical depth}

It is not easy to match the modeled sea-salt optical depth to optical depth measurements either from ground or from space, since the measured optical depths contain the impact from all the aerosol species. Sea-salt seldom dominates the marine optical depth. Therefore, to compare our model optical depth with AERONET (AErosol RObotic NETwork) retrievals, we choose Midway Island in the middle of the Pacific Ocean, which is away from dust storm tracks, biomassburning smoke plumes, and anthropogenic pollution sources. Smirnov et al. (2003) stated Midway as the only AERONET site where they could clearly separate the sea-salt optical depth. We compare the model sea salt optical depths (including all particle sizes in the computation) with the observed coarse-mode optical depth. The coarse-mode optical depth is the wavelength independent part of the optical depth. Use of the coarse mode optical depth should lessen the contribution of small particles that are likely not sea-salt. To further exclude the seasonal impacts from other aerosol sources, we eliminate the data points when the instantaneous optical depths are over 0.3 .

Figure 8 compares the AERONET optical depth at Midway Island with the monthly-averaged model optical depth using Gong, Caffrey, and CMS source functions for 2006. The AERONET data after September are not considered reliable, and therefore are not shown. Note that mass data as in Fig. 6 is not available for 2006, so we could not compare mass and optical depth for the same year. Here we average the daytime model output when AERONET retrievals are available (January to September). The root mean squares of the difference between the simulated optical depth and the AERONET optical depth are 0.042, 0.040, and 0.026 for Gong, Caffrey, and CMS source functions, respectively, so CMS source function gives the best fit. As we can see from the source function in Fig. 2, the elevated $0.1-1 \mu \mathrm{m}$ size range 
of the CMS source function leads to higher optical depth and better fit to the AERONET retrievals.

\subsubsection{Relationship between optical depth and wind speed}

Madry et al. (2011) have shown that a useful constraint on SSA optical depth can be obtained from its wind speed dependence. A correlation between wind speed and sea-salt optical depth has been suggested by many researchers (Hoppel et al., 1990; Smirnov et al., 2003; Satheesh et al., 2006; Mulcahy et al., 2008). However, considerable scatter about this correlation may remain due to wind speed variations on short time scales, pollution in the boundary layer and free-troposphere/stratosphere aerosols contributing to optical depth. Evident correlation can be obtained only when stable atmospheric conditions are being experienced and uniform clean marine air masses are being studied. A power-law relationship

$\tau_{\lambda=500 \mathrm{~nm}}=0.06+0.00055 \cdot U^{2.195}$

with a high correlation $\left(r^{2}=0.97\right)$ was found for wind speed up to $18 \mathrm{~m} \mathrm{~s}^{-1}$ at Mace Head, Ireland (Mulcahy et al., 2008). The analysis was carried out under stable wind conditions and very stringent criteria for selecting the clean marine air mass. To ensure that the measured optical depth properties are representative of the corresponding wind speed conditions, Mulcahy et al. (2008) filtered their samples by "stable wind condition", which required daily standard deviation of wind speed less than $2 \mathrm{~m} \mathrm{~s}^{-1}$ and standard deviation during optical depth measurements less than $1 \mathrm{~m} \mathrm{~s}^{-1}$. Only 14 days out of 10 months of data were left for analyzing the optical depth-wind speed dependence. Other datasets show similar dependence over a wide area .(Smirnov et al., 2003; Satheesh et al., 2006). Madry et al. (2011) found that a seasalt model produced similar wind speed dependence over the global ocean.

We use the dependence of Mulcahy et al. (2008) with the modeled 10 meter wind speed to constrain model optical depth in 2006. Our model wind field is the 6-hourly NCEP reanalysis wind fields linearly interpolated to a 30minute time step and therefore the high-frequency variation of wind speed is smoothed out. We defined the "stable wind condition" by requiring the daily standard deviation of the wind speed be less than $1 \mathrm{~m} \mathrm{~s}^{-1}$. On average about $35 \%$ of the model days are filtered out using this constraint. The constant term (0.06) in optical depth-wind speed dependence of Mulcahy et al. (2008) reflects the wind-independent optical depth component, which includes the contribution of residual sea-salt and other aerosol species that are not included in our model simulation. Those aerosols could be marine sulfate aerosol derived from dimethylsulfide, marine organic aerosol, and anthropogenic aerosol transported from the continents. Our model results indicate that the optical
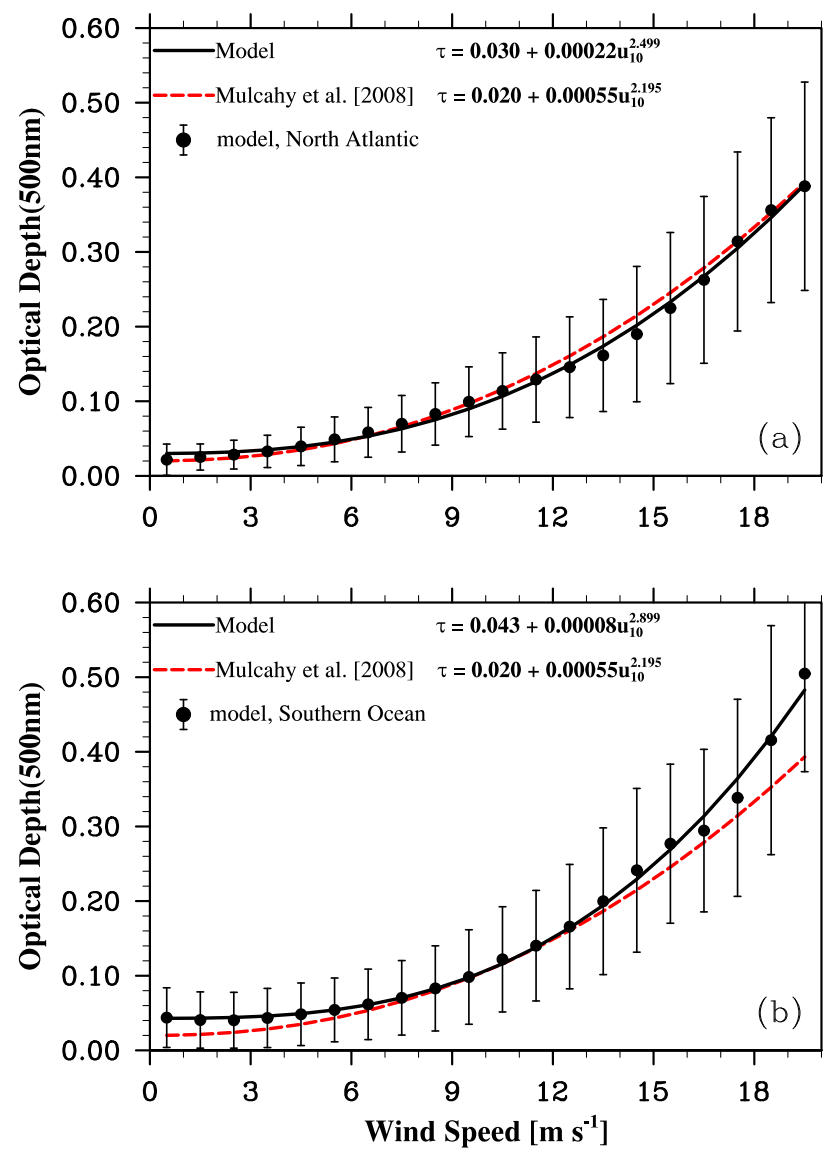

Fig. 9. Wind speed dependence of sea-salt optical depth in (a) North Atlantic and (b) roaring forties $\left(60^{\circ} \mathrm{S}-40^{\circ} \mathrm{S}\right)$ in 1994 . Dots are the modeled yearly-averaged optical depths displayed in the middle of the wind speed interval. Error bars represent one standard deviation of the values in the region. The dashed lines are the optical depths of the power-law relationship of Mulcahy et al. (2008) using model $10 \mathrm{~m}$ wind speed with constant term scaled down to 0.02 . The model used the CMS source function and a solubility factor of 0.5 .

depth under windless condition (the constant term) with seasalt only is less than 0.06. The power-law optical depthwind speed dependence is well reproduced by our model by scaling Mulcahy et al.'s constant term down from 0.06 to 0.02 . Table 3 shows that the simulated global sea-salt optical depths in 1994 using the CMS source function and the solubility factor of 0.5 is well reproduced by the Mulcahy et al. function. The Gong source function underestimates the optical depths from the Mulcahy et al. function even with low solubility factor of 0.3 .

Figure 9 shows the modeled optical depth at a wavelength of $500 \mathrm{~nm}$ as a function of wind speed in the North Atlantic and the "roaring forties" (See Table 4 for definitions of these locations). Optical depths in the "roaring forties" grow with wind speed more rapidly at high wind conditions in our model than in the formulation based on Mulcahy et al.'s 
Table 4. Aerosol optical depth $(\tau)$-wind speed $\left(u_{10}\right)$ dependence of the fitting function in global oceanic regions.

\begin{tabular}{llllccc}
\hline Region & \multicolumn{2}{c}{ Coordinate } & Optical depth-wind speed & MSE & $R$ & $\%_{\text {Stable wind }}$ \\
\hline N. Atlantic & $\mathrm{EQ}-60^{\circ} \mathrm{N}$ & $75^{\circ} \mathrm{W}-180^{\circ} \mathrm{W}$ & $\tau=0.030+0.00022 u_{10} 2.499$ & $5.84 \times 10^{-5}$ & 0.9967 & $72.8 \%$ \\
S. Atlantic & $60^{\circ} \mathrm{S}-\mathrm{EQ}$ & $75^{\circ} \mathrm{W}-20^{\circ} \mathrm{E}$ & $\tau=0.026+0.00063 u_{10} 2.143$ & $1.19 \times 10^{-4}$ & 0.9961 & $62.0 \%$ \\
N. Pacific & $\mathrm{EQ}-60^{\circ} \mathrm{N}$ & $145^{\circ} \mathrm{E}-120^{\circ} \mathrm{W}$ & $\tau=0.037+0.00001 u_{10} 2.767$ & $9.56 \times 10^{-5}$ & 0.9944 & $73.4 \%$ \\
S. Pacific & $60^{\circ} \mathrm{S}-\mathrm{EQ}$ & $150^{\circ} \mathrm{E}-75^{\circ} \mathrm{W}$ & $\tau=0.036+0.00001 u_{10} 3.007$ & $1.23 \times 10^{-4}$ & 0.9898 & $72.4 \%$ \\
Indian Ocean & $60^{\circ} \mathrm{S}-30^{\circ} \mathrm{N}$ & $20^{\circ} \mathrm{E}-145^{\circ} \mathrm{E}$ & $\tau=0.017+0.00041 u_{10} 2.374$ & $2.44 \times 10^{-5}$ & 0.9990 & $70.5 \%$ \\
Roaring Forties & $60^{\circ} \mathrm{S}-40^{\circ} \mathrm{S}$ & $0^{\circ} \mathrm{E}-0^{\circ} \mathrm{W}$ & $\tau=0.042+0.00017 u_{10} .659$ & $1.38 \times 10^{-5}$ & 0.9967 & $45.2 \%$ \\
Southern Ocean & $65^{\circ} \mathrm{S}-60^{\circ} \mathrm{S}$ & $0^{\circ} \mathrm{E}-0^{\circ} \mathrm{W}$ & $\tau=0.043+0.00080 u_{10} 2.899$ & $1.10 \times 10^{-4}$ & 0.9911 & $49.9 \%$ \\
\hline
\end{tabular}

MSE: mean square error. $R$ : Correlation.

coefficients. Table 4 shows the power-law fits of the modeled optical depth-wind speed dependence in seven oceanic regions. The mean squared error (MSE) of the fitting functions show that the modeled optical depths are well represented by the quadratic power-law relationship. The correlations between the calculated optical depth from Mulcahy et al.'s relationship and the model are as high as 0.99. Although the power-law relationship is applicable in all the regions, differences can be found in the coefficients. The exponent is generally larger than the 2.195 value in Mulcahy et al.'s relationship when derived from our model, indicating stronger enhancement of optical depth with increased wind speed in the model. Figure 10 shows the scatter plot comparing latitudinal-averaged optical depth from the model and calculated from Mulcahy et al.'s formula from $70^{\circ} \mathrm{S}$ to $70^{\circ} \mathrm{N}$. The slope of 0.97 and correlation of 0.93 indicates the model and the function derived from the measurements agree very well over the global oceans. The normalized mean bias is -0.044 . Similar high correlations were found by Madry et al. (2011). Note that the variability in the modeled optical depths denoted by the error bars are so large that the differences in the power laws from Mulcahy et al. (2008) and our model are not significant. While Mulcahy's data come from a very restricted part of the oceans, it is interesting that both our model and Madry et al. (2011)'s model suggest similar behavior may occur over much of the world's ocean.

\subsection{Number concentration}

Unfortunately, it is even more difficult to find data on seasalt number concentration than on optical depth. Most condensation nuclei $(\mathrm{CN})$ and cloud condensation nuclei $(\mathrm{CCN})$ data do not distinguish aerosol composition. In addition, there are no data from a network on $\mathrm{CN}$ and $\mathrm{CCN}$, as there are for optical depth and mass. Many researchers have carried out investigations on the wind speed dependence of marine aerosol number concentration as reviewed by Lewis and Schwartz (2004). Only a few of them discriminated SSA from other marine aerosols using the thermal heating technique (O'Dowd and Smith, 1993; Shinozuka et al., 2004).

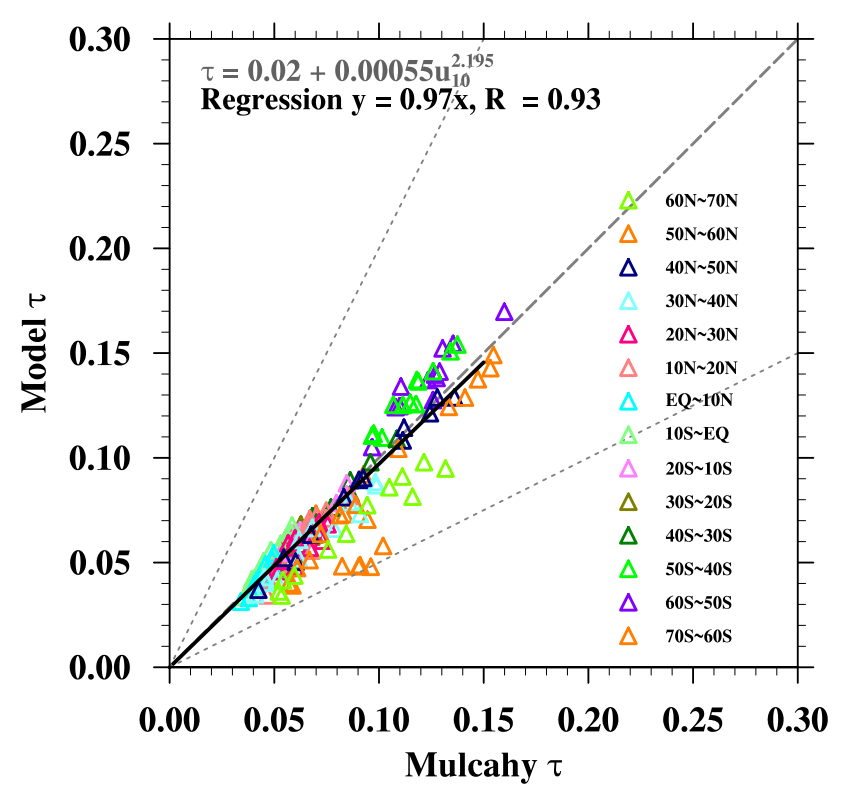

Fig. 10. Modeled optical depth model compared with calculated optical depth by Mulcahy et al. (2008) wind speed-optical depth relationship in 1994. The slope of the regression line and the correlation $(R)$ are shown. The long dash line is the one-to-one line and the short dash lines are one-to-two and two-to-one lines. Each triangle is a monthly-mean of a $10^{\circ}$ latitude region. Colors represent the latitudes. The model used the CMS source function and a solubility factor of 0.5 .

The wind speed dependence of SSA number concentration, $N$, is typically expressed by a log-linear relationship

$\log N=a_{N} u_{10}+N_{0}$

Here $a_{N}$ is slope of the wind speed dependence and $N_{0}$ is the exponential of the number concentration at windless condition. Figure 11 compares our model results in October 1994 with the ship measurements over the Northeast Atlantic $\left(63^{\circ} \mathrm{N}, 8^{\circ} \mathrm{W}\right)$ by O'Dowd and Smith (1993) in October 1989 down to radius as small as $0.05 \mu \mathrm{m}$. The data cover wind speeds as high as $17 \mathrm{~m} \mathrm{~s}^{-1}$. Here we interpolate 


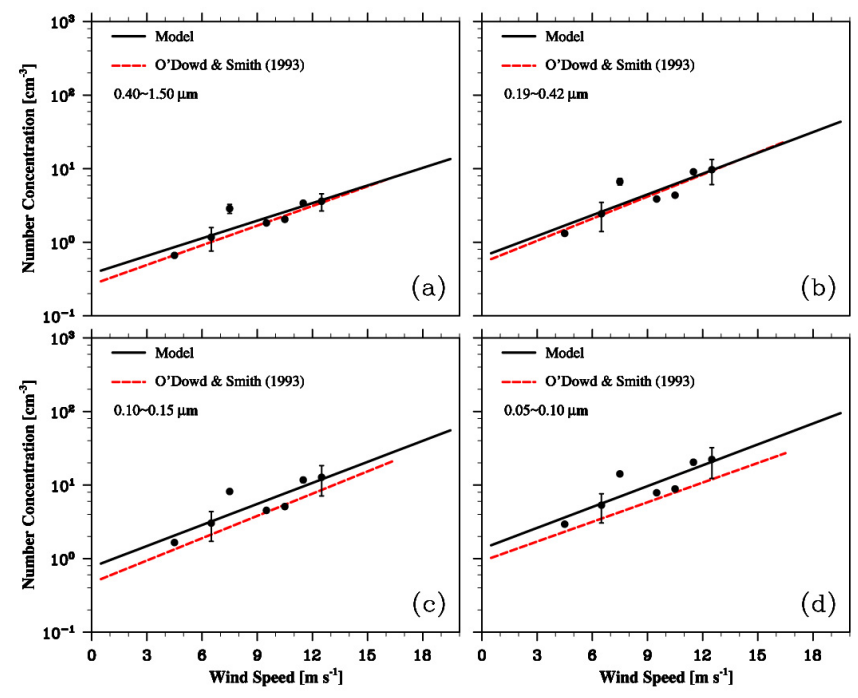

Fig. 11. Wind speed dependence of the number concentration in the model compared with measurements by O'Dowd and Smith (1993) during October 1994 in the Northeast Atlantic $\left(63^{\circ} \mathrm{N}, 8^{\circ} \mathrm{W}\right)$ in the dry radius range (a) $0.40-1.50 \mu \mathrm{m}$, (b) $0.19-0.42 \mu \mathrm{m}$, (c) 0.10 $0.15 \mu \mathrm{m}$, and (d) $0.05-0.10 \mu \mathrm{m}$. The dots are the modeled number with error bars representing one standard deviation. The solid lines are the linear fits. The model used the CMS source function and a solubility factor of 0.5 .

the model size ranges to the four size ranges of the measurement. The model results generally agree with the measurements in all four size ranges. However, the model produce higher concentrations for the particles with radius of $0.05-0.1 \mu \mathrm{m}$ than observed. We conclude from the comparison between model and the measurement that the reasonable range of $a_{N}$ coefficients varies from 0.08 to 0.10 for radius smaller than $1.5 \mu \mathrm{m}$ for the measurement location. We also compare our model in December 1994 with the First Aerosol Characterization Experiment (ACE-1) dataset. We averaged the model concentration over the ACE-1 campaign region in the southwest Pacific $\left(40-56^{\circ} \mathrm{S}, 135-160^{\circ} \mathrm{E}\right)$ and compared with ACE-1 data in November and December 1995 (Shinozuka et al., 2004) in Fig. 12. Also included in Fig. 12 are the data obtained by O'Dowd and Smith (1993). We use their data instead of the regression fit because we would have higher number concentration at high wind speeds using their regression function than the actual data. The ACE-1 data are for submicron size ranges $(0.075-0.5 \mu \mathrm{m})$ and the O'Dowd and Smith (1993) data are for size ranges $0.05-0.15 \mu \mathrm{m}$, and $0.19-0.42 \mu \mathrm{m}$. The model size range is interpolated to be as consistent as possible with the measurement data $(0.075-$ $0.15 \mu \mathrm{m}, 0.19-0.42 \mu \mathrm{m})$. Both measurements show a nearzero offset while the model offset is about $10 \mathrm{~cm}^{-3}$. The different offset between the model and the data could be due to the a different rainout rate in the year that was modeled, which brings more SSA from the upwind direction, than actually occurred during the year of the measurements. The

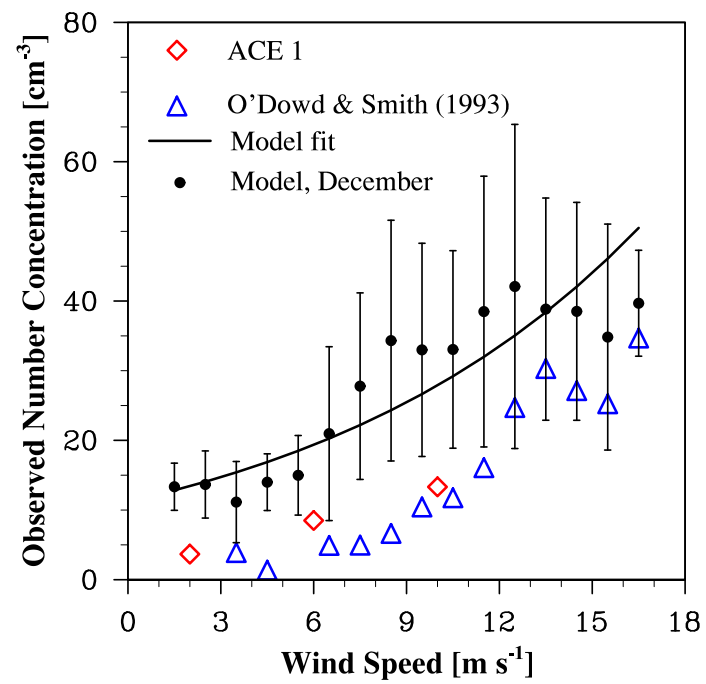

Fig. 12. Wind dependence of number concentration of the model in the South Pacific compared to the function of O'Dowd and Smith (1993) and the ACE-1 data. The error bars represent one-standard deviation of the model results. The model and O'Dowd and Smith data are for dry radius $0.05-0.15 \mu \mathrm{m}$ and $0.19-0.42 \mu \mathrm{m}$. The ACE-1 data are for radius $0.075-0.5 \mu \mathrm{m}$. The model used the CMS source function and a solubility factor of 0.5 . Figure 12 indicates the model values have a zero wind offset (of about $10 \mathrm{~cm}^{-3}$ ), which is larger than the observed zero wind speed offset.

regression fit to the model results generally agrees with the wind speed dependence of the measurements although the model fit is higher than the measurements at moderate wind speeds $\left(7-13 \mathrm{~m} \mathrm{~s}^{-1}\right)$. We explored whether the model overestimate could be caused by the rainfall evaporation scheme, which releases particles back at their original size when raindrops evaporate. In reality aerosols should merge inside drops to form larger particles. We find model number concentrations are reduced by about $8.6 \%$ if we let the small particles grow into larger ones after rain droplets evaporate, which is not enough to explain the overestimation. It also could result from the lack of condensational growth of $\mathrm{SO}_{2}$ gas onto sea salt particles in our model. Such growth would lead to larger particles which may influence which particles sizes are compared between the model and observations.

At wind speeds above $13 \mathrm{~m} \mathrm{~s}^{-1}$ the model number concentration falls below the regression line in Fig. 12. Figure 13 illustrates the modeled wind speed dependence of the emission flux compared with the eddy covariance measurements of sea spray particle emission by Norris et al. (2008). The data are fitted to a log-linear relationship between the fluxes and the wind speed. The model emission flux is a power-law relationship with the wind speed so the shape is different than the data, but we still give the log-linear fits in the figure. Smaller slopes for the model are found for particles with radius of $0.15 \mu \mathrm{m}$ as well as other size ranges not shown here. The model produces less SSA particles than 


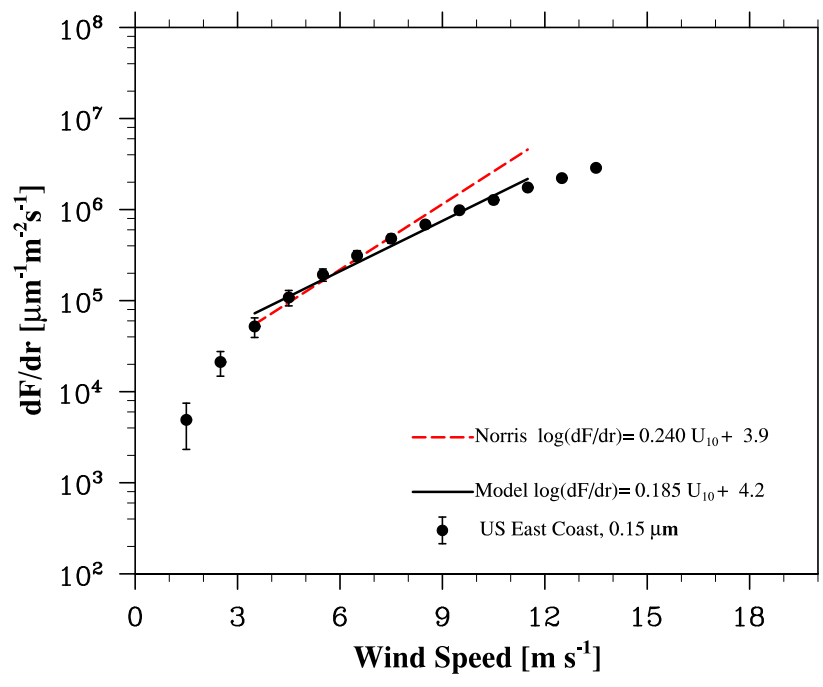

Fig. 13. Emission fluxes of $0.15 \mu \mathrm{m}$ dry radius sea-salt at different wind speeds. The dots with error bars are the model parameterized emission fluxes. The solid line is the log-linear fit for wind speed range $4-12 \mathrm{~m} \mathrm{~s}^{-1}$. The dashed line is the emission flux by Norris et al. (2008). The model values were averaged over the area of ship measurement at the United States east coast $\left(24-36^{\circ} \mathrm{N}, 50-77^{\circ} \mathrm{W}\right)$. The model used the CMS source function and a solubility factor of 0.5 .

from the relationship derived from the measurement at high wind speeds. Therefore, it is possible that some mechanism that could increase the production rate at high wind speed is not included in the existing source functions. Alternatively the Norris et al. (2008) data may be affected by being taken in a coastal region, or by other local factors.

\subsection{Size distribution}

\subsubsection{Comparison with AERONET size distribution}

Particle size distributions for radius from 0.05 to $15 \mu \mathrm{m}$ are retrieved by AERONET using a flexible inversion algorithm developed by Dubovik and King (2000). Figure 14a demonstrates the AERONET-derived and model-produced volumetric size distribution under ambient relative humidity at Midway Island in January, June, and September 2006. AERONET size distributions are retrieved in actual (wet) particle radius. Therefore, we also display the model results in wet radius. Particles with the same dry radius could grow into different wet sizes because of the different relative humidity values in different vertical layers. To facilitate combining the functions in various vertical layers, we define a set of "universal wet radius bins", which extends to $82.7 \mu \mathrm{m}$. We first calculate the wet radius at each layer for each of our original dry salt bins. Then we redistribute the particles to the "universal wet radius bins" in such a way that both the dry mass and the number are conserved in the splitting.
AERONET reports volume size distribution in their data products. However, the light scattering mainly depends on the cross-sectional area of the particles. Hence we believe the data are actually more reliable for area distribution. Therefore, we convert the AERONET volumetric size distribution, $d V / d \ln r$, to the area size distribution, $d V / d \ln r$, by

$$
\frac{d A}{d \ln r}=\frac{3}{4 r} \frac{d V}{d \ln r}
$$

where $A$ is the cross-sectional area. The results are shown in Fig. 14b. Different scales are used for the model and the AERONET retrieval so that the total volume and crosssectional area are the same for the model and AERONET for particles larger than $0.44 \mu \mathrm{m}$. We make the areas equal above $0.44 \mu \mathrm{m}$ because AERONET shows a significant mode near $0.1 \mu \mathrm{m}$. This mode is probably due to sulfate and organic aerosols from the oceans or pollution aerosols that are not represented in the model. Notice that this mode is weaker in January when the biota is less active.

The modeled size distribution basically reflects the coarse mode in the AERONET bi-modal size distribution inversion. The model volumetric size distributions show two modes, one near $3 \mu \mathrm{m}$ and the other near $30 \mu \mathrm{m}$. Clearly a significant amount of volume is in the very large mode, which comes from spume generation. The data do not show the presence of the spume mode probably because AERONET retrievals are not sensitive to volume but to area. The model spans to larger sizes, but is questionable because the spume droplet generation is hard to observe and may be poorly represented in the model. The large particles may not instantaneously grow to equilibrium state with ambient relative humidity as we assumed in the model. The spume mode contributes little to the area of the particles. The shape of the modeled area size distribution basically matches the coarse-mode AERONET size distribution, though there are variations from month to month.

\subsubsection{Comparison with in-situ measurement}

Since it is not possible to determine the number concentration of SSA in the AERONET retrievals, we compare our modeled size distribution with in-situ measurements at the surface. Figure 15 shows the modeled number size distributions using Gong, Caffrey, and CMS source functions at Midway Island in June 2006. Comparison are made to the observation during the NEAT' 89 cruise in Northeast Atlantic (O'Dowd et al., 1997). A tri-modal log-normal function is fitted to the measurements for film, jet, and spume droplet modes,

$$
\frac{d N}{d \log r}=\sum_{i=1,3} \frac{N_{i}}{\ln \sigma_{i} \sqrt{2 \pi}} e^{-\frac{\left(\ln (r)-\ln \left(r_{\mathrm{mi}}\right)\right)^{2}}{2 \ln ^{2} \sigma_{i}}}
$$



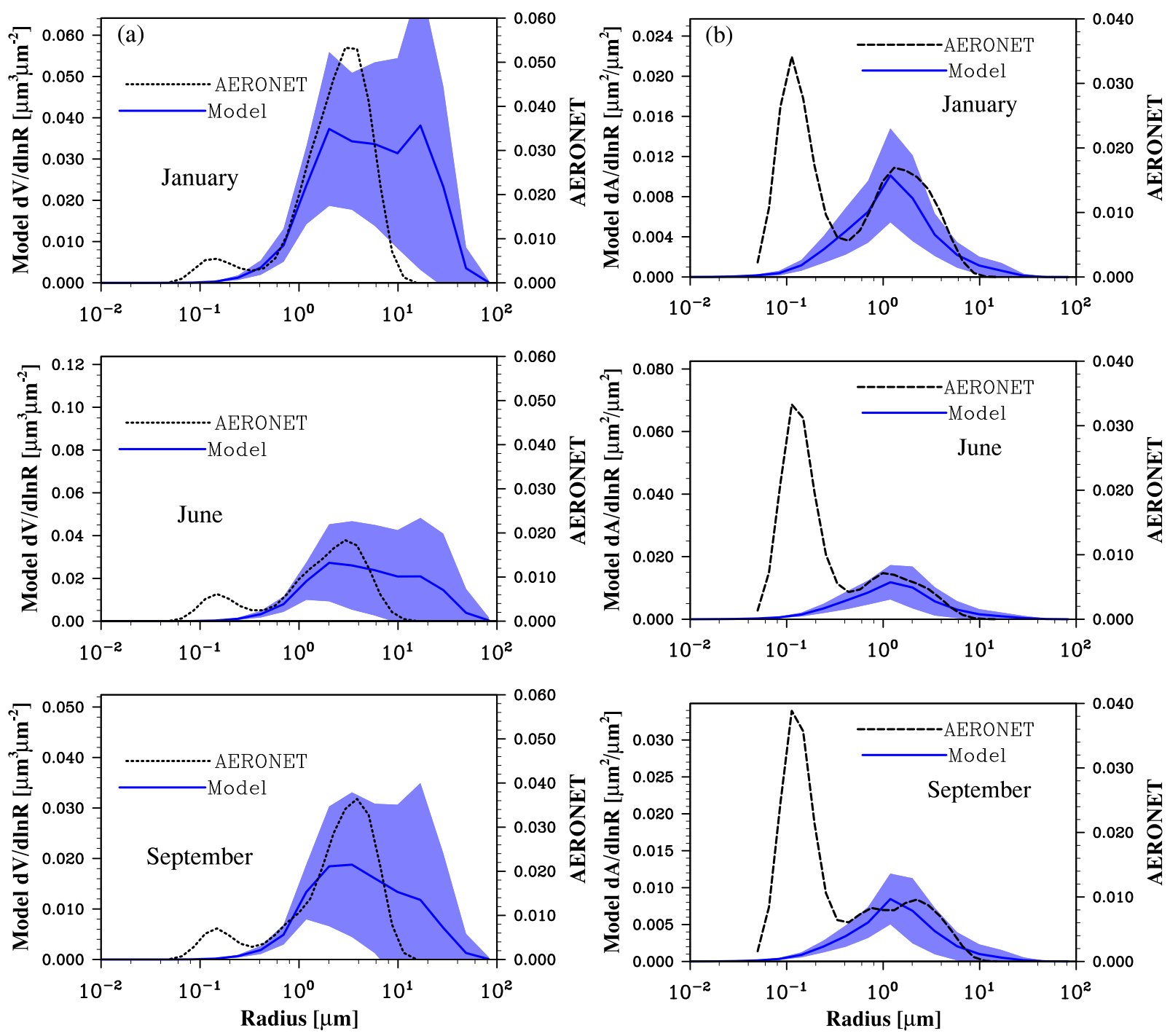

Fig. 14. (a) volumetric size distribution s a function of wet radius compared between the vertical integration of the simulations and AERONET inversion product at Midway Island in March, June, and September 2006. The shaded area around the model curve is one standard deviation of all the daily size distributions; (b) same as (a) but for cross-sectional area size distribution. The model used the CMS source function and a solubility factor of 0.5. Different vertical scale are used for the model and AERONET to make the total volume and cross-sectional area the same for particles larger than $0.44 \mu \mathrm{m}$.

$i=1,2,3$ for film, jet and spume, where $N_{i}$ is the total number concentration for that mode, $r_{\mathrm{mi}}$ is the mode radius and $\sigma_{i}$ is the standard deviation.

$\log N_{1}=0.095 u_{10}+0.283, \quad r_{m 1}=0.1 \mu \mathrm{m}, \quad \sigma_{1}=1.9(26)$

$\log N_{2}=0.0422 u_{10}-0.288, \quad r_{m 2}=1 \mu \mathrm{m}, \quad \sigma_{2}=2$

$\log N_{3}=0.069 u_{10}-3.5, \quad r_{m 3}=6 \mu \mathrm{m}, \quad \sigma_{3}=3$

We correct the wet radius given by the measurement data to dry radius. We apply the correction of the equations given by Vignati et al. (2001). The applicable range of the data is $0.05-15 \mu \mathrm{m}$ of dry radius.
Also shown in Fig. 15 is the canonical distribution from Lewis and Schwartz (2004), which is an empirical relationship that is based on 21 measurements of size distributions of SSA concentrations over the global oceans (refer to Table 13 in Lewis and Schwartz, 2004), which includes the measurement of O'Dowd et al. (1997). The canonical size distribution is

$\frac{d N}{d \log _{10} r_{80}}=n_{0} e^{\left\{-\frac{1}{2}\left[\frac{\ln \left(r_{80} / r_{80}^{\prime}\right)}{\ln \sigma}\right]^{2}\right\}}$

where $n_{0}=0.07 u_{10}^{2}, r_{80}$ is the radius at relative humidity of $80 \%, r_{80}^{\prime}=0.3 \mu \mathrm{m}$ is the geometric mean radius, and $\sigma=2.8$ 


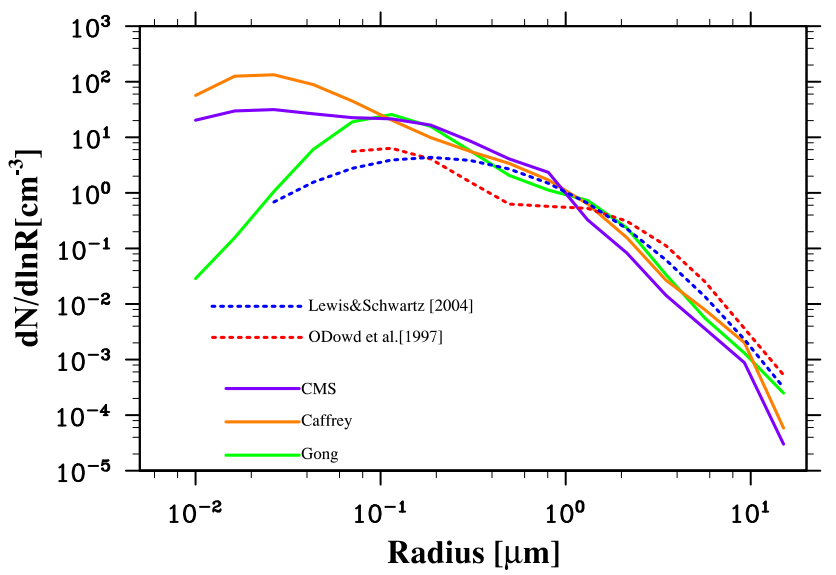

Fig. 15. Surface number size distribution versus dry radius compared between the modeled distribution and Lewis and Schwartz (2004) canonical distribution and O'Dowd et al. (1993) empirical relationship at Midway Island in June 2006. The model used a solubility factor of 0.5 . We multiply the whole size distributions by normalizing factors of 2.241, 0.891, 2.038, and 1.849 for Lewis and Schwartz (2004), O’Dowd et al. (1993), Gong, and Caffrey function, respectively.

is the geometric standard deviation. Here we use the model $10 \mathrm{~m}$ wind speed for the functions suggested by O'Dowd et al. (1997) and Lewis and Schwartz (2004). The measurements were taken under various conditions that may introduce uncertainties, however, the shape of the source function does not depend on wind speed except for spume while the flux is a strong function of wind speed. Hence, one expects the shape to be less variable than the absolute abundance. We multiply the whole size distributions by a normalizing factor so that the modeled and measured cross sectional areas for particles larger than $0.07 \mu \mathrm{m}$ are equal to that of the CMS model result.

Figure 15 shows that the model number concentration in the coarse mode $(1-15 \mu \mathrm{m})$ from the three source functions matches the measurements within an order of magnitude. The model number concentrations of the three source functions in the $0.1-1 \mu \mathrm{m}$ size range have very similar shapes and also match the canonical size distribution in the $0.5-1 \mu \mathrm{m}$ size range within an order of magnitude. The function of O'Dowd et al. (1997) is lower than the model results in the $0.5-1 \mu \mathrm{m}$ size range, which could due to the gap between two-modes in the fitting function. The major difference between the three source functions comes from particles in the size range $0.01-0.1 \mu \mathrm{m}$ that dominate the number concentration. However, very few measurements in this size range are incorporated in the canonical size distribution.

A recent study that extends down to ultra-fine SSA particles examined the thermal stability and growth factor of the marine aerosol particles in a wide range of sizes (Clarke et al., 2006). Figure 16 shows that the percentages of particles

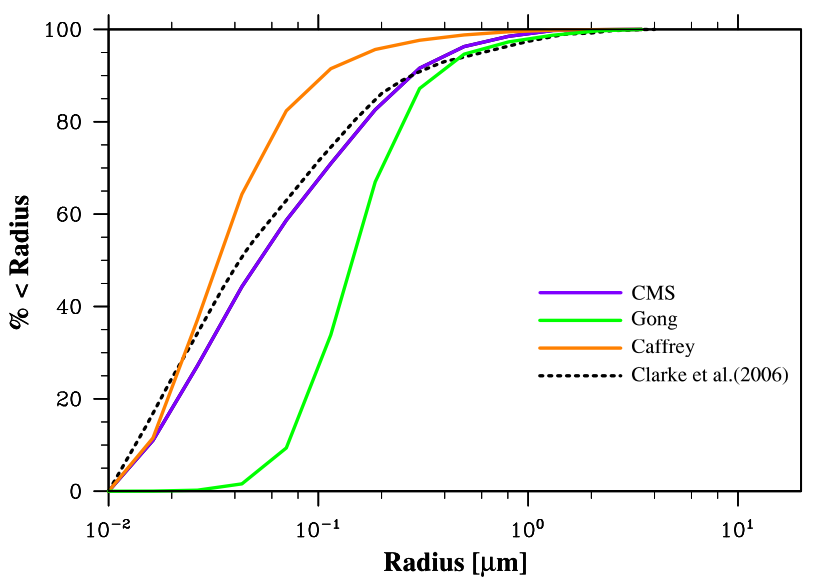

Fig. 16. Percentage of number concentration with dry radius larger than the value indicated in the model bottom layer compared between model results using Gong, Caffrey and CMS source function and Clarke et al. (2006). The model size distributions are from the grid cell containing the Midway Island in June 2006. The model used a solubility factor of 0.5 .

smaller than a certain particle radius using the CMS source function agrees with the measurement of Clarke et al. (2006). Note that we have converted the diameter range of $0.01-8 \mu \mathrm{m}$ in Clarke et al. 's figure to the radius range and reconstructed the percentage distribution to be in the range of $0.01-4 \mu \mathrm{m}$. Clarke et al.'s data shows that $54.8 \%$ of sea-salt particles are smaller than 0.05 in dry radius. We list the number concentration and the fraction of the particles smaller than $0.05 \mu \mathrm{m}$ from our model and the canonical size distribution by Lewis and Schwartz (2004) in Table 5. The Gong source function gives about $10 \%$ of sea-salt number coming from particles smaller than $0.05 \mu \mathrm{m}$, which is close to the canonical size distribution but much lower than $54.8 \%$ as observed. The Caffrey and CMS source functions give a much larger fraction of around $85 \%$ and $60 \%$ of particles smaller than $0.05 \mu \mathrm{m}$, because they are based on Clarke et al. (2006), which indicates the existence of large amount of ultra-fine SSA particles. CMS gives the closest estimate for the fraction of particles smaller than $0.05 \mu \mathrm{m}$. The Gong source function rejected the small particles in the Monahan source function (see Fig. 1).

Figure 17 shows the mass and cross-sectional area size distribution compared with that inferred from the Lewis and Schwartz (2004) canonical size distribution. They are normalized in the same way as Fig. 15. The mass and the cross-sectional area distribution in the coarse mode match the canonical size distribution very well for the Gong and Caffrey source functions. The CMS source function gives a relatively lower coarse mode. Note that this does not mean CMS source function underpredicts coarse mode particles as Fig. 17 is normalized. All source functions for mass produce results which agree with the canonical one in the radius 

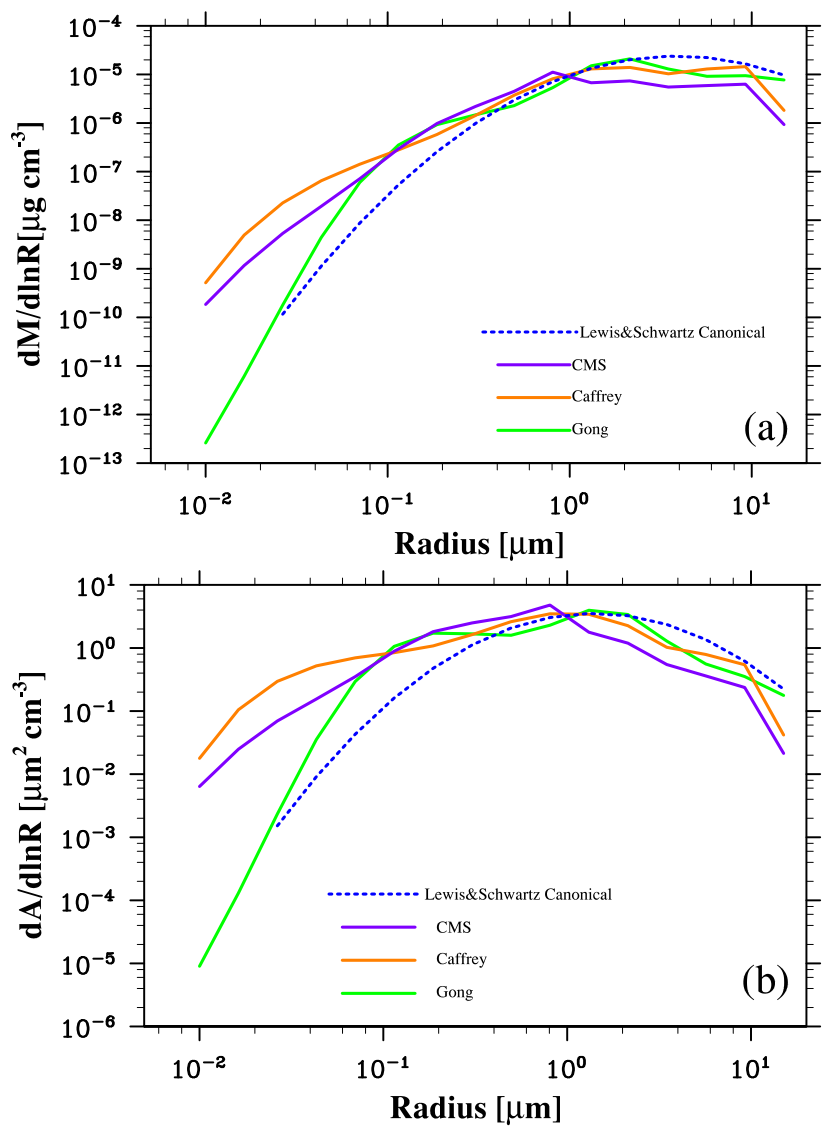

Fig. 17. Same as Fig. 15 except for (a) mass and (b) cross-sectional area size distribution.

range from 0.1 to $1 \mu \mathrm{m}$. The differences in the mass and cross-sectional area below $0.1 \mu \mathrm{m}$ are not important for the integrated mass and area due to their small magnitude.

Figure 18 shows the percentages of modeled number, cross-sectional area, and mass concentration smaller than a certain particle radius using the CMS source function. The radius at which the number, area, and mass concentration reaches $50 \%$ of the total is $0.051 \mu \mathrm{m}, 0.93 \mu \mathrm{m}$, and $1.6 \mu \mathrm{m}$, respectively. Although it is commonly agreed that mass and number are dominated by difference size ranges, it is not very often mentioned that the mass and optical depth are dominated by different sizes. Climate models usually reproduce mass and they assume optical depth should also be well represented. Figure 18 shows that it is not an absolutely correct assumption.

\subsection{SSA global distribution}

Figure 19 shows the global distribution of optical depth using the CMS source function in the boreal winter and summer of 2006. The optical depths are usually high $(>0.1)$ in the roaring forties $\left(40^{\circ}-60^{\circ} \mathrm{S}\right)$ in the Southern Hemisphere where the wind blows fiercely all through the year. The

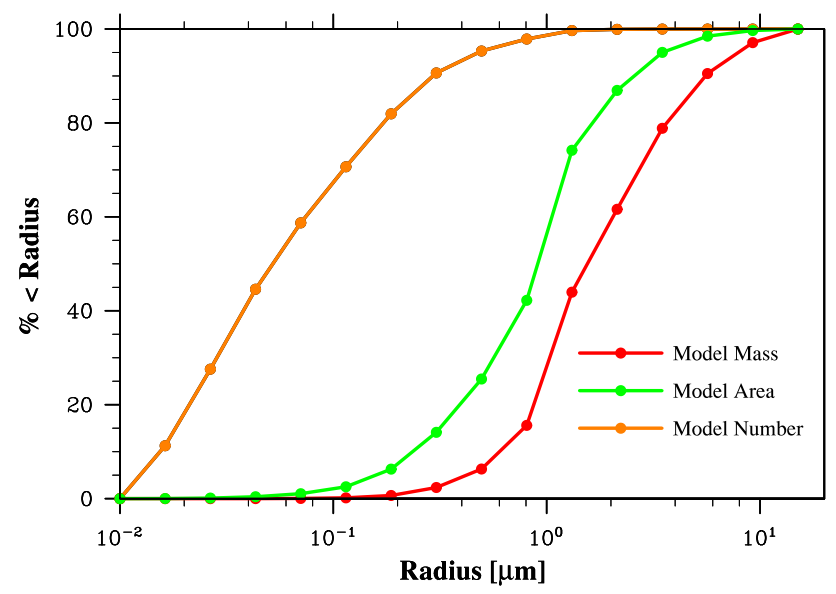

Fig. 18. Percentage of number, cross-sectional area, and mass size distribution less than a particular radius in the dry radius range from 0.01-15.2 $\mu \mathrm{m}$. The number and mass concentration are for bottom layer. The cross-sectional area is calculated for humidified particles in the whole column. These are the size distributions at Midway Island in June 2006 using the CMS source function and a solubility factor of 0.5 .

Table 5. Monthly-averaged number concentration with radius 0.01$4 \mu \mathrm{m}$ and fraction of particles with radius of $0.01-0.05 \mu \mathrm{m}$ at Midway Island in June 2006.

\begin{tabular}{llr}
\hline Source functions/ data & $\begin{array}{l}\text { Number concentration } \\
\left(\mathrm{cm}^{-3}\right)\end{array}$ & Fraction \\
\hline Gong & 17.3 & $9.4 \%$ \\
Caffrey & 120.8 & $82.4 \%$ \\
CMS & 83.7 & $58.7 \%$ \\
Clarke et al. (2006) & N/A & $54.8 \%$ \\
Lewis and Schwartz (2004) & 4.5 & $10.1 \%$ \\
\hline
\end{tabular}

optical depths are also relatively large in the high-latitude oceans of the Northern Hemisphere in winter when the wind strengthens. The optical depths are low in the tropical region in both seasons due to the low wind speeds. The optical depth increases in the summer monsoon season over the Indian Ocean. Basically the optical depth distribution follows the wind speed pattern. Tropical rainfall could also contribute to low optical depth by the removal of SSA particles. The high optical depths near Peru result from the error in the NCEP wind field near the Andes Mountains (personal communication with Dr. J. F. Lamarque, 2008).

Figure 20 shows the global distribution of number concentration in the surface layer in the size range of $0.01-15 \mu \mathrm{m}$ in the boreal winter and summer of 2006 . The concentration is typically about $10-50 \mathrm{~cm}^{-3}$, but can be over $150 \mathrm{~cm}^{-3}$ in the "roaring forties". Persistent high concentrations exist in the "roaring forties" in the two seasons. Low values can be 


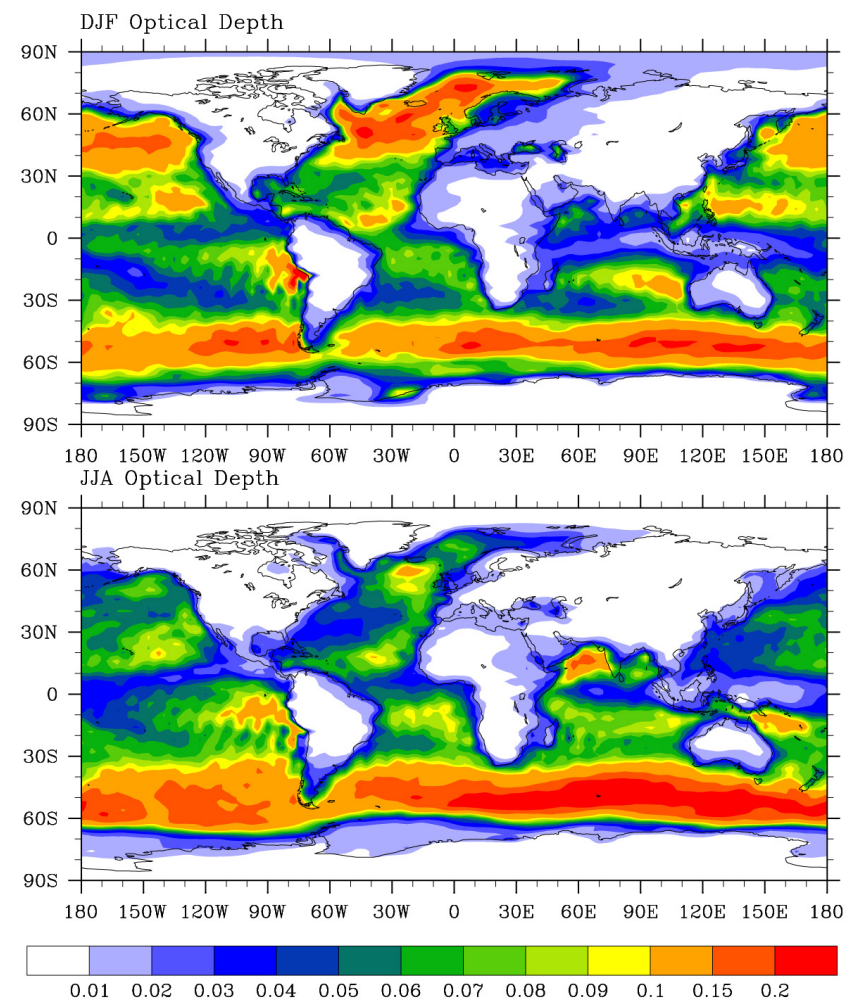

Fig. 19. Modeled global distribution of SSA optical depth in the boreal winter (DJF, December, January, and February) and summer (JJA, June, July, and August) of 2006. The model used the CMS source function and a solubility factor of 0.5 .

seen in the tropics and again high concentration in the summer monsoon season over India Ocean. The "hot spot" off the coast of South America is due to the error in the wind field as in Fig. 19. However, the seasonal variation of number concentrations does not correspond with that of the wind speed or optical depth. Although it is true for every season that the number concentration increases with wind speed, the increases are different between seasons. For example referring to Fig. 19 the optical depth is highest over the North Pacific, North Atlantic and roaring forties in the winter for the hemisphere in question, while the number density is highest in summer.

The different seasonal patterns of optical depth and number concentration are likely due to the different removal mechanisms in different particle size ranges. Figure 21 shows the loss rate of particles as a function of radius for $30-60^{\circ} \mathrm{N}$ and $30-60^{\circ} \mathrm{S}$ in boreal summer and winter. Dry deposition, wet scavenging and total loss rate are shown in Fig. 21. The loss rates are calculated by dividing the global removal flux by the global concentration (Balkanski et al., 1993). In both seasons and hemispheres wet scavenging is the dominant process removing particles smaller than about $1 \mu \mathrm{m}$. Therefore, the number concentration is influenced by wet scavenging as well as wind speed which controls the pro-
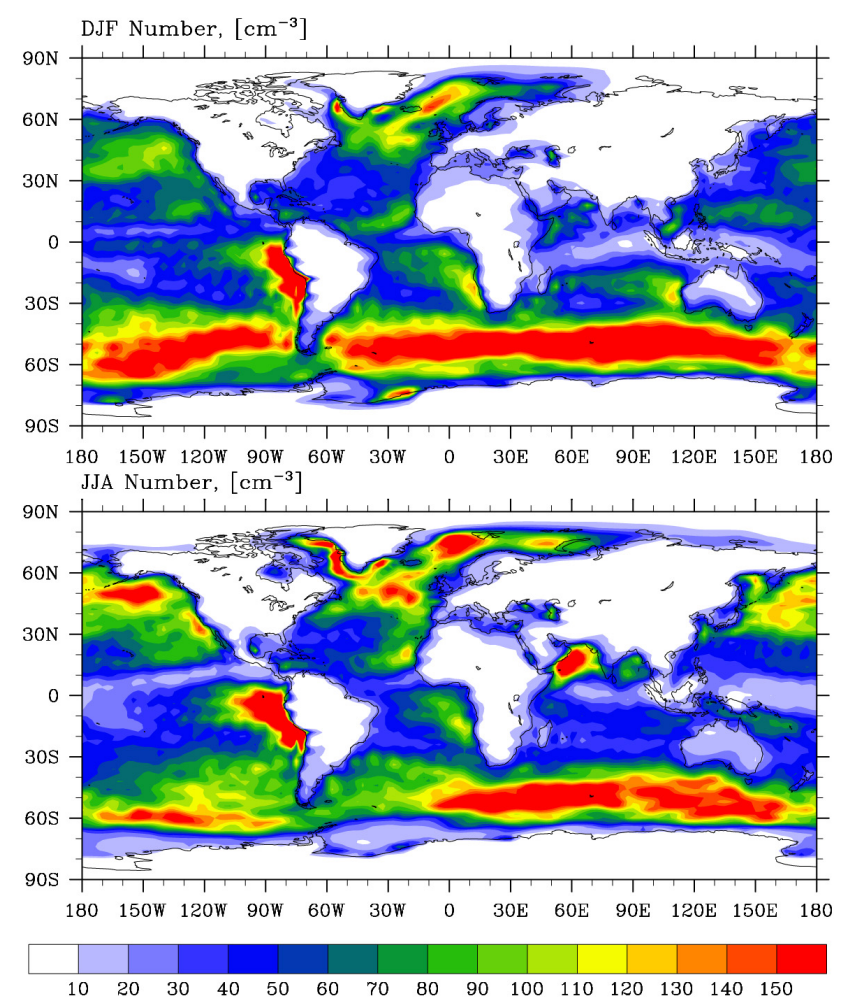

Fig. 20. Modeled global distribution of SSA surface number concentration in the boreal winter (DJF, December, January, and February) and summer (JJA, June, July, and August) of 2006. The model used the CMS source function and a solubility factor of 0.5 .

duction rate. Although the emission in the Northern Hemisphere during boreal winter is higher than in summer, precipitation removes SSA particles more effectively in winter so the number concentration in Northern Hemisphere increase from winter to summer. In contrast to the situation for small particles, the optical depth is mostly influenced by particles larger than $1 \mu \mathrm{m}$. Dry deposition is important for particles larger than $1 \mu \mathrm{m}$ in both winter and summer. Dry deposition depends only weakly on wind speed, and not at all on rainfall. Therefore, the optical depth pattern follows the wind speed because the emission as a function of wind speed controls the concentration.

Figure 22 illustrates the $\mathrm{CCN}$ number concentration at a supersaturation of $0.1 \%$, which is a subset of number concentration with radius larger than $0.07 \mu \mathrm{m}$. Typically our modeled sea-salt could contribute $10-20 \mathrm{~cm}^{-3}$ to the CCN in the tropics and as much as $100 \mathrm{~cm}^{-3}$ to the $\mathrm{CCN}$ in the "roaring forties". The CNN "hot spot" off the South America is due to an error in the NCEP wind field as mentioned in Figs. 19 and 20. CCN follow the same seasonal pattern as the extra-tropical number concentration being highest in summer when there are fewer rainfall events. Korhonen et al. (2008) simulates the $\mathrm{CCN}$ (radius $>0.066 \mu \mathrm{m}$ ) concentrations in the range from 100 to $300 \mathrm{~cm}^{-3}$ in January and less 

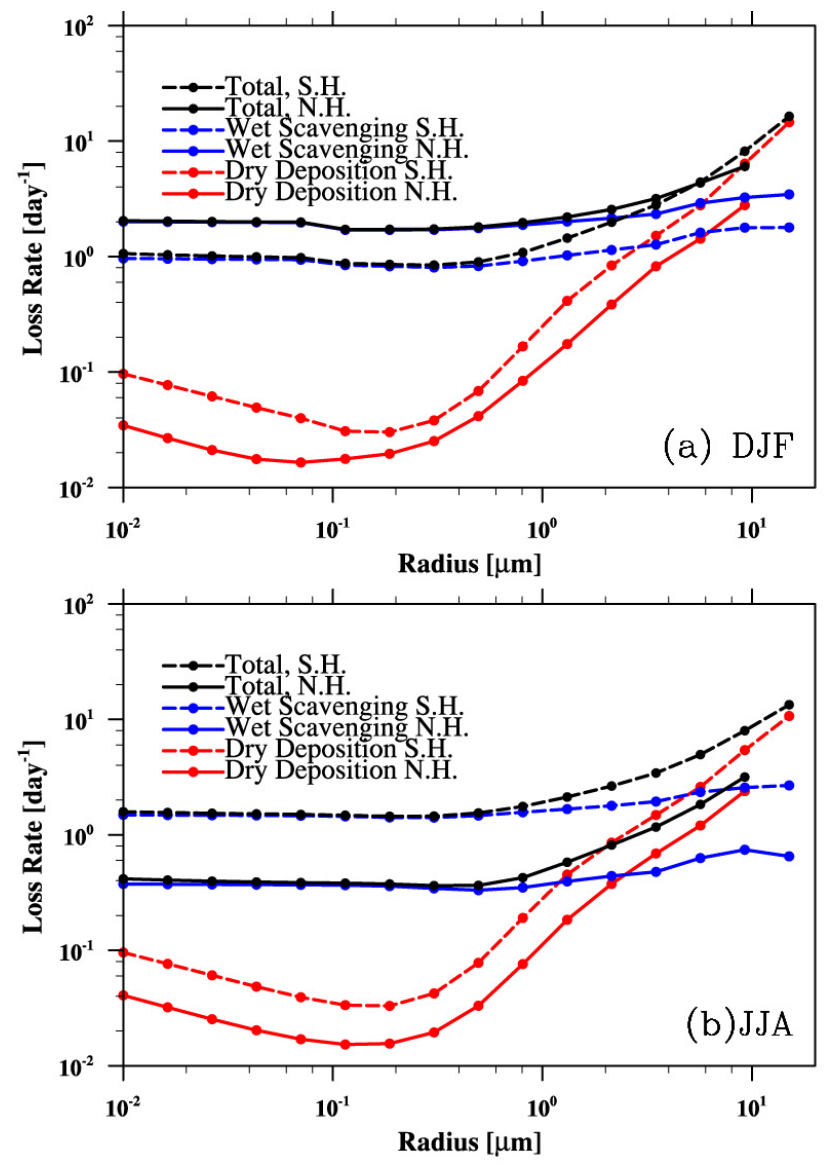

Fig. 21. The dry deposition, wet scavenging and total loss rate of particles as a function of dry radius for $30-60^{\circ} \mathrm{N}$ (Northern Hemisphere, N. H.) and 30-60 S (Southern Hemisphere, S. H.) in (a) June, July, and August (JJA) and (b) December, January, February (DJF). The model used a solubility factor of 0.5 .

than $100 \mathrm{~cm}^{-2}$ in July in the "roaring forties" with Dimethylsulfide (DMS) emission turned off. Our prediction is lower with $20 \sim 100 \mathrm{~cm}^{-3}$ in December, January and February and $10 \sim 100 \mathrm{~cm}^{-3}$ in June, July, and August. This difference between the models could be partially due to the Mårtensson source function used in Korhonen et al. (2008) producing more ultrafine particles in the cold high latitudes. In addition, $\mathrm{SO}_{2}$, which is included in the Korhonen model, could contribute to the formation of $\mathrm{CCN}$ in the pristine Southern Ocean even without DMS. Both models shows a similar spatial pattern in the Southern Ocean with the maximum concentration in the region near $90^{\circ} \mathrm{E}$ in January and between $45-90^{\circ} \mathrm{E}$ in July with minimum in the south Pacific. The two models also have consistent seasonal variation in which the $\mathrm{CCN}$ number peaks in the summer when the precipitation is weaker.
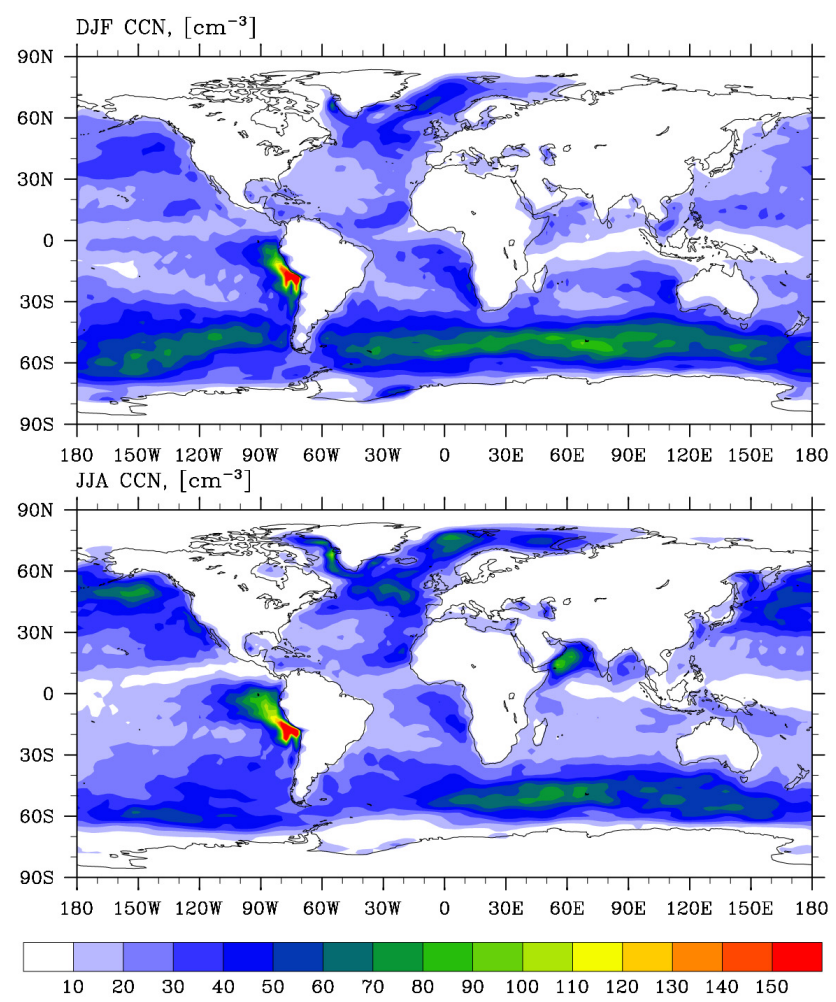

Fig. 22. Modeled global distribution of marine boundary layer $\mathrm{CCN}$ at supersaturation of $0.1 \%$ in the boreal winter (DJF, December, January, and February) and summer (JJA, June, July, and August) of 2006. The model used the CMS source function and a solubility factor of 0.5 .

\section{Conclusions}

We develop an SSA model based on a coupled climate and microphysical model CAM/CARMA with detailed aerosol and dynamical processes. A combined CMS source function, inspired by Caffrey et al. (2006), that incorporates different source functions from the literature in various size ranges into one source function, has been compared with other traditional source functions. Mass, optical depth, and number concentration are well modeled. The advantages of the CMS source function in modeling mass, optical depth, number concentrations, as well as the size distribution are illustrated in Table 3 and Fig. 16.

While the focus in the literature has generally been on source functions, we find that removal processes are equally important. We adjust the wet scavenging rate in our model so that the corresponding residence time is consistent with the AEROCOM estimation. We find that SSA mass and optical depth peak in the winter, when winds are highest. However, surprisingly, particle numbers and $\mathrm{CCN}$ concentrations peak in summer when rainfall is lowest. This difference in seasonal behavior is due to the fact that the particles controlling mass and optical depth have significant removal rates due to 
sedimentation, while the small particles that control number are lost by rainout and washout.

Although data, which are now becoming old, exist for seasalt mass, there are relatively few datasets for optical depth and number concentration that are specific to sea-salt. One way to isolate sea-salt is through wind speed relationships. However, data seem particularly lacking for SSA less than $0.1 \mu \mathrm{m}$ and for larger spume droplets. Based on available measurements, the model reproduces the wind-dependence of the SSA optical depth measured by Mulcahy et al. (2008) in Ireland, though we also notice that the modeled dependence varied slightly among different oceans. The "roaring forties" tends to have larger optical depth at higher wind speed in the model than suggested from the Mulcahy formulation.

We find good agreement between the model and the wind speed dependence of the number concentration found at one measurement location. The wind dependence is also well reproduced by the model on a regional scale when compared to multiple datasets. However, the model over predicts the zero wind speed number concentrations. We did not model the same years when the data were obtained, so this difference in zero wind speed concentrations may reflect different rainfall amounts between the modeled year and the observed year. The fraction of particles smaller than $0.05 \mu \mathrm{m}$ modeled by the CMS source function agrees well with measurements. The model estimates a CCN concentration from sea-salt of about $10-20 \mathrm{~cm}^{-3}$ in the tropics and as high as $100 \mathrm{~cm}^{-3}$ in the "roaring forties".

The modeled SSA particle size distribution agrees well with the AERONET coarse-mode area size distribution. We do not think AERONET size distribution inversion products are suitable for sea-salt volume.

Obviously sea-salt is not an isolated aerosol species in the marine environment. Sulfate and organic aerosols as well as their gaseous precursors co-exist in the marine environment. The large surface area of sea-salt as well as its large $\mathrm{pH}$ value facilitates the condensation of precursor gases, such as $\mathrm{SO}_{2}$, and their subsequent oxidation. Coagulation of sulfate aerosols with sea-salt aerosol will change the marine $\mathrm{CN}$ spectrum, which in turn influences the $\mathrm{CCN}$ activation and removal processes. We are aware that the interactions between sea-salt and other marine aerosol species influence the emission, removal, and optical properties of the sea-salt aerosols. These interactions are not currently included in our simulation. Although we have been making effort to utilize datasets that are limited to sea-salt aerosol, the role of other species can influence some of our conclusions. For example, condensational growth of sea-salt by $\mathrm{SO}_{2}$ and organic vapor from marine biota can accelerate the dry deposition process. Therefore the model could overestimate the mass concentration and optical depth to some extent.

There are issues in addition to including other types of aerosols that also need to be considered further in future modeling. Tuning of the wet deposition in the model will still be necessary for future sulfate-containing simulations. The solubility factor should be evaluated again for mixed sea-salt-sulfate aerosol. The constant term in the wind-speed dependence of optical depth could be much closer to 0.06 as in Mulcahy et al. (2008) when sulfate aerosol is incorporated. We need more extensive data bases on marine sea-salt and other marine aerosols to further constrain models. Our conclusions are restricted to the dataset we used. More sizeand chemical-resolved data will be especially useful in understanding sea-salt and other marine aerosol species. This work is the basis for future studies we plan of marine aerosol direct and indirect effects using the coupled CAM/CARMA model.

Acknowledgements. We thank William Madry for helpful discussions about this work, and Charles Bardeen for help meshing CARMA and CAM. We thank the Brent Holben and his colleagues for their effort in establishing and maintaining AERONET Midway Island sites. This work was supported by NSF grant ATM-0856007.

Edited by: K. Lehtinen

\section{References}

Andreas, E. L.: Model estimates of the effects of sea spray on airsea heat fluxes, Mar. Sci. Inst., Univ. of Conn., Avery Point Groton, 17-28, 1990.

Andreas, E. L.: A new sea spray generation function for wind speeds up to $32 \mathrm{~m} \mathrm{~s}^{-1}$, J. Phys. Oceanogr., 28, 2175-2184, 1998.

Andreas, E. L., Edson, J. B., Monahan, E. C., Rouault, M. P., and Smith, S. D.: The spray contribution to net evaporation from the sea - a review of recent progress, Bound-Lay. Meteorol., 72, 3 52,1995

Ayash, T., Gong, S., and Jia, C. Q.: Direct and indirect shortwave radiative effects of sea salt aerosols, J. Climate, 21, 3207-3220, doi:10.1175/2007jcli2063.1, 2008.

Balkanski, Y. J., Jacob, D. J., Gardner, G. M., Graustein, W. C., and Turekian, K. K.: Transport and residence times of tropospheric aerosols inferred from a global 3-dimensional simulation of $\mathrm{Pb}$ 210, J. Geophys. Res., 98, 20573-20586, 1993.

Bardeen, C. G., Toon, O. B., Jensen, E. J., Marsh, D. R., and Harvey, V. L.: Numerical simulations of the three-dimensional distribution of meteoric dust in the mesosphere and upper stratosphere, $\mathrm{J}$. Geophys. Res., 113, D17202, doi:10.1029/2007jd009515, 2008.

Bardeen, C. G., Toon, O. B., Jensen, E. J., Hervig, M.E., Randall, C. E., Benze,S., Marsh, D. R., and Merkel, A.: Numerical simulations of the three-dimensional distribution of polar mesospheric clouds and comparisons with Cloud Imaging and Particle Size (CIPS) experiment and the Solar Occultation For Ice Experiment (SOFIE) observations, J. Geophys. Res., 115, D10204, doi:10.1029/2009JD012451, 2010.

Bates, T. S., Coffman, D. J., Covert, D. S., and Quinn, P. K.: Regional marine boundary layer aerosol size distributions in the Indian, Atlantic, and Pacific Oceans: A comparison of INDOEX measurements with ACE-1, ACE-2, and Aerosols99, J. Geophys. Res., 107(15), 8026, doi:10.1029/2001jd001174, 2002.

Burk, S. D.: The generation, turbulent transfer and deposition of the sea-salt aerosol, J. Atmos. Sci., 41, 3040-3049, 1984. 
Caffrey, P. F., Hoppel, W. A., and Shi, J. J.: A one-dimensional sectional aerosol model integrated with mesoscale meteorological data to study marine boundary layer aerosol dynamics, J. Geophys. Res., 111, D24201, doi:10.1029/2006jd007237, 2006.

Clarke, A. D., Owens, S. R., and Zhou, J. C.: An ultrafine sea-salt flux from breaking waves: Implications for cloud condensation nuclei in the remote marine atmosphere, J. Geophys. Res., 111, D06202, doi:10.1029/2005jd006565, 2006.

Collins, W. D., Rasch, P. J., Boville, B. A., Hack, J. J., McCaa, J. R., Williamson, D. L., Briegleb, B. P., Bitz, C. M., Lin, S. J., and Zhang, M. H.: The formulation and atmospheric simulation of the Community Atmosphere Model version 3 (CAM3), J. Climate, 19, 2144-2161, 2006.

Dana, M. T. and Hales, J. M.: Statistical aspects of washout of polydisperse aerosols, Atmos. Environ., 10, 45-50, 1976.

DeBell, L. J., Gebhart, K. A., Hand, J. L., Malm, W. C., Pitchford, M. L., Schichtel, B. A., and White, W. H.: Spatial and seasonal patterns and temporal variability of haze and its constituents in the United States Report IV, Cooperative Institute for Research in the Atmosphere, 217-218, 2006.

Deng, Y., Bowman, K. P., and Jackson, C.: Differences in rain rate intensities between TRMM observations and community atmosphere model simulations, Geophys. Res. Lett., 34, L01808, doi:10.1029/2006g1027246, 2007.

Dubovik, O. and King, M. D.: A flexible inversion algorithm for retrieval of aerosol optical properties from Sun and sky radiance measurements, J. Geophys. Res., 105, 20673-20696, 2000.

Fitzgerald, J. W.: Marine aerosols - a review, Atmos. Environ., 25, 533-545, 1991.

Fitzgerald, J. W., Hoppel, W. A., and Gelbard, F.: A onedimensional sectional model to simulate multicomponent aerosol dynamics in the marine boundary layer -1 . Model description, J. Geophys. Res., 103, 16085-16102, 1998.

Gerber, H. E.: Relative-Humidity Parameterization of the Navy Aerosol Model (NAM), Naval Research Laboratory, Washington, DC, 1985.

Gong, S. L.: A parameterization of sea-salt aerosol source function for sub- and super-micron particles, Global. Biogeochem. Cy., 17, 1097, doi:10.1029/2003gb002079, 2003.

Grini, A., Myhre, G., Sundet, J. K., and Isaksen, I. S. A.: Modeling the annual cycle of sea salt in the global 3-D model Oslo CTM2: Concentrations, fluxes, and radiative impact, J. Climate, 15, 1717-1730, 2002.

Haywood, J. M., Ramaswamy, V., and Soden, B. J.: Tropospheric aerosol climate forcing in clear-sky satellite observations over the oceans, Science, 283, 1299-1303, 1999.

Hoppel, W. A., Fitzgerald, J. W., Frick, G. M., Larson, R. E., and Mack, E. J.: Aerosol Size Distributions and Optical-Properties Found in the Marine Boundary-Layer over the Atlantic-Ocean, J. Geophys. Res., 95, 3659-3686, 1990.

Hoppel, W. A., Caffrey, P. F., and Frick, G. M.: Particle deposition on water: Surface source versus upwind source, J. Geophys. Res., 110, D10206, doi:10.1029/2004jd005148, 2005.

Jacobson, M. Z.: Global direct radiative forcing due to multicomponent anthropogenic and natural aerosols, J. Geophys. Res., 106, 1551-1568, 2001.

Jaeglé, L., Quinn, P. K., Bates, T. S., Alexander, B., and Lin, J.-T.: Global distribution of sea salt aerosols: new constraints from in situ and remote sensing observations, Atmos. Chem. Phys., 11,
3137-3157, doi:10.5194/acp-11-3137-2011, 2011.

Justus, C. G., Hargraves, W. R., Mikhail, A., and Graber, D.: Methods for estimating wind speed frequency distribution, J. Appl. Meteorol., 17, 350-353, 1978.

Kalnay, E., Kanamitsu, M., Kistler, R., Collins, W., Deaven, D., Gandin, L., Iredell, M., Saha, S., White, G., Woollen, J., Zhu, Y., Chelliah, M., Ebisuzaki, W., Higgins, W., Janowiak, J., Mo, K. C., Ropelewski, C., Wang, J., Leetmaa, A., Reynolds, R., Jenne, R., and Joseph, D.: The NCEP/NCAR 40-year reanalysis project, B. Am. Meteorol. Soc., 77, 437-471, 1996.

Korhonen, H., Carslaw, K. S., Spracklen, D. V., Mann, G. W., and Woodhouse, M. T.: Influence of oceanic dimethyl sulfide emissions on cloud condensation nuclei concentrations and seasonality over the remote Southern Hemisphere oceans: A global model study, J. Geophys. Res., 113, D15204, doi:10.1029/2007JD009718, 2008.

Large, W. G. and Pond, S.: Sensible and Latent-Heat Flux Measurements over the Ocean, J. Phys. Oceanogr., 12, 464-482, 1982.

Lewis, E. R. and Schwartz, S. E.: Sea salt aerosol production. Mechanisms, methods, measurements, and models, American Geophysical Union, Washington, DC,USA, 2004.

Ma, X., von Salzen, K., and Li, J.: Modelling sea salt aerosol and its direct and indirect effects on climate, Atmos. Chem. Phys., 8, 1311-1327, doi:10.5194/acp-8-1311-2008, 2008.

Madry, W. L., Toon, O. B., and O'Dowd, C. D.: Modeled optical thickness of sea?salt aerosol, J. Geophys. Res.,116, D08211, doi:10.1029/2010JD014691, 2011.

Mårtensson, E. M., Nilsson, E. D., de Leeuw, G., Cohen, L. H., and Hansson, H. C.: Laboratory simulations and parameterization of the primary marine aerosol production, J. Geophys. Res., 108, 4297, doi:10.1029/2002jd002263, 2003.

Monahan, E. C. and O'Muircheartaigh, I. G.: Whitecaps and the passive remote sensing of the ocean surface, Int. J. Remote Sens., 7, 627-642, 1986.

Monahan, E. C., Spiel, D. E., and Davidson, K. L.: A model of marine aerosol generation via whitecaps and wave disruption, in: Oceanic whitecaps and their role in air-sea exchange processes, edited by: MacNiocaill, E. C. M. G., Reidel, Dordrecht, The Netherlands, 167-174, 1986.

Mulcahy, J. P., O’Dowd, C. D., Jennings, S. G., and Ceburnis, D.: Significant enhancement of aerosol optical depth in marine air under high wind conditions, Geophys. Res. Lett., 35, L16810, doi:10.1029/2008g1034303, 2008.

Murphy, D. M., Anderson, J. R., Quinn, P. K., McInnes, L. M., Brechtel, F. J., Kreidenweis, S. M., Middlebrook, A. M., Posfai, M., Thomson, D. S., and Buseck, P. R.: Influence of sea-salt on aerosol radiative properties in the Southern Ocean marine boundary layer, Nature, 392, 62-65, 1998.

Norris, S. J., Brooks, I. M., de Leeuw, G., Smith, M. H., Moerman, M., and Lingard, J. J. N.: Eddy covariance measurements of sea spray particles over the Atlantic Ocean, Atmos. Chem. Phys., 8, 555-563, doi:10.5194/acp-8-555-2008, 2008.

O'Dowd, C. D. and Smith, M. H.: Physicochemical properties of aerosols over the northeast Atlantic - evidence for wind-speedrelated submicron sea-salt aerosol production, J. Geophys. Res., 98, 1137-1149, 1993.

O’Dowd, C. D., Smith, M. H., Consterdine, I. E., and Lowe, J. A.: Marine aerosol, sea-salt, and the marine sulphur cycle: A short review, Atmos. Environ., 31, 73-80, 1997. 
O’Dowd, C. D., Lowe, J. A., and Smith, M. H.: Coupling sea-salt and sulphate interactions and its impact on cloud droplet concentration predictions, Geophys. Res. Lett., 26, 1311-13-14, 1999.

Penner, J. E., Andreae, M., Annegarn, H., Barrie, L., Feichter, J., Hegg, D., Jayaraman, A., Leaitch, R., Murphy, D., Nganga, J., and Pitari, G., et al.: Aerosols, their Direct and Indirect Effects, in: Climate Change 2001: The Scientic? Basis, Contribution of Working Group I to the Third Assessment Report of the Intergovernmental Panel on Climate Change, edited by: Houghton, J. T., Cambridge, 289-348, 2001.

Pierce, J. R. and Adams, P. J.: Global evaluation of CCN formation by direct emission of sea salt and growth of ultrafine sea salt, J. Geophys. Res., 111, D06203, doi:10.1029/2005jd006186, 2006.

Quinn, P. K., Coffman, D. J., Kapustin, V. N., Bates, T. S., and Covert, D. S.: Aerosol optical properties in the marine boundary layer during the First Aerosol Characterization Experiment (ACE1) and the underlying chemical and physical aerosol properties, J. Geophys. Res., 103, 16547-16563, 1998.

Satheesh, S. K., Srinivasan, J., and Moorthy, K. K.: Contribution of sea-salt to aerosol optical depth over the Arabian Sea derived from MODIS observations, Geophys. Res. Lett., 33, L03809, doi:10.1029/2005g1024856, 2006.

Savoie, D. L. and Prospero, J. M.: Aerosol Concentration Statistics for Northern Tropical Atlantic, J. Geophys. Res., 82, 5954-5964, 1977.

Savoie, D. L., Prospero, J. M., Arimoto, R., and Duce, R. A.: Non-sea-salt sulfate and methanesulfonate at American Samoa, J. Geophys. Res., 99(D2), 3587-3596, 1994.

Shinozuka, Y., Clarke, A. D., Howell, S. G., Kapustin, V. N., and Huebert, B. J.: Sea-salt vertical profiles over the Southern and tropical Pacific oceans: Microphysics, optical properties, spatial variability, and variations with wind speed, J. Geophys. Res., 109, D24201, doi:10.1029/2004jd004975, 2004.

Smirnov, A., Holben, B. N., Eck, T. F., Dubovik, O., and Slutsker, I.: Effect of wind speed on columnar aerosol optical properties at Midway Island, J. Geophys. Res., 108, 4802, doi:10.1029/2003jd003879, 2003.
Smith, M. H., Park, P. M., and Consterdine, I. E.: Marine aerosol concentrations and estimated fluxes over the sea, Q. J. Roy. Meteor. Soc., 119, 809-824, 1993.

Stramska, M.: Vertical profiles of sea salt aerosol in the atmospheric surface layer: A numerical model, Acta. Geophys. Polonica, 35, 87-100, 1987.

Su, L. and Toon O. B.: Numerical simulations of Asian dust storms using a coupled climate-aerosol microphysical model, J. Geophys. Res., 114, D14202, doi:10.1029/2008JD010956, 2009.

Su, L. and Toon, O. B.: Saharan and Asian dust: similarities and differences determined by CALIPSO, AERONET, and a coupled climate-aerosol microphysical model, Atmos. Chem. Phys., 11, 3263-3280, doi:10.5194/acp-11-3263-2011, 2011.

Textor, C., Schulz, M., Guibert, S., Kinne, S., Balkanski, Y., Bauer, S., Berntsen, T., Berglen, T., Boucher, O., Chin, M., Dentener, F., Diehl, T., Easter, R., Feichter, H., Fillmore, D., Ghan, S., Ginoux, P., Gong, S., Grini, A., Hendricks, J., Horowitz, L., Huang, P., Isaksen, I., Iversen, I., Kloster, S., Koch, D., Kirkevåg, A., Kristjansson, J. E., Krol, M., Lauer, A., Lamarque, J. F., Liu, X., Montanaro, V., Myhre, G., Penner, J., Pitari, G., Reddy, S., Seland, Ø., Stier, P., Takemura, T., and Tie, X.: Analysis and quantification of the diversities of aerosol life cycles within AeroCom, Atmos. Chem. Phys., 6, 1777-1813, doi:10.5194/acp-61777-2006, 2006.

Toon, O. B., Turco, R. P., Westphal, D., Malone, R., and Liu, M. S.: A multidimensional model for aerosols - description of computational analogs, J. Atmos. Sci., 45, 2123-2143, 1988.

Vignati, E., de Leeuw, G., and Berkowicz, R.: Modeling coastal aerosol transport and effects of surf-produced aerosols on processes in the marine atmospheric boundary layer, J. Geophys. Res., 106, 20225-20238, 2001.

Winter, B. and Chylek, P.: Contribution of sea salt aerosol to the planetary clear-sky albedo, Tellus B, 49, 72-79, 1997.

Zhang, L. M., Gong, S. L., Padro, J., and Barrie, L.: A sizesegregated particle dry deposition scheme for an atmospheric aerosol module, Atmos. Environ., 35, 549-560, 2001. 